\title{
Automated Extraction System Design Review
}

\author{
H. L. Parry \\ J. D. Eklund \\ J. M. Halter \\ R. G. Sullivan
}

March 1979

Prepared for the U.S. Department of Energy under Contract EY-76-C-06-1830

Pacific Northwest Laboratory Operated for the U.S. Department of Energy by Battelle Memorial Institute 


\section{NOTICE}

This report was prepared as an account of work sponsored by the United States Government. Neither the United States nor the Department of Energy, nor any of their employees, nor any of their contractors, subcontractors, or their employees, makes any warranty, express or implied, or assumes any legal liability or responsibility for the accuracy, completeness or usefulness of any information, apparatus, product or process disclosed, or represents that its use would not infringe privately owned rights.

The views, opinions and conclusions contained in this report are those of the contractor and do not necessarily represent those of the United States Government or the United States Department of Energy.

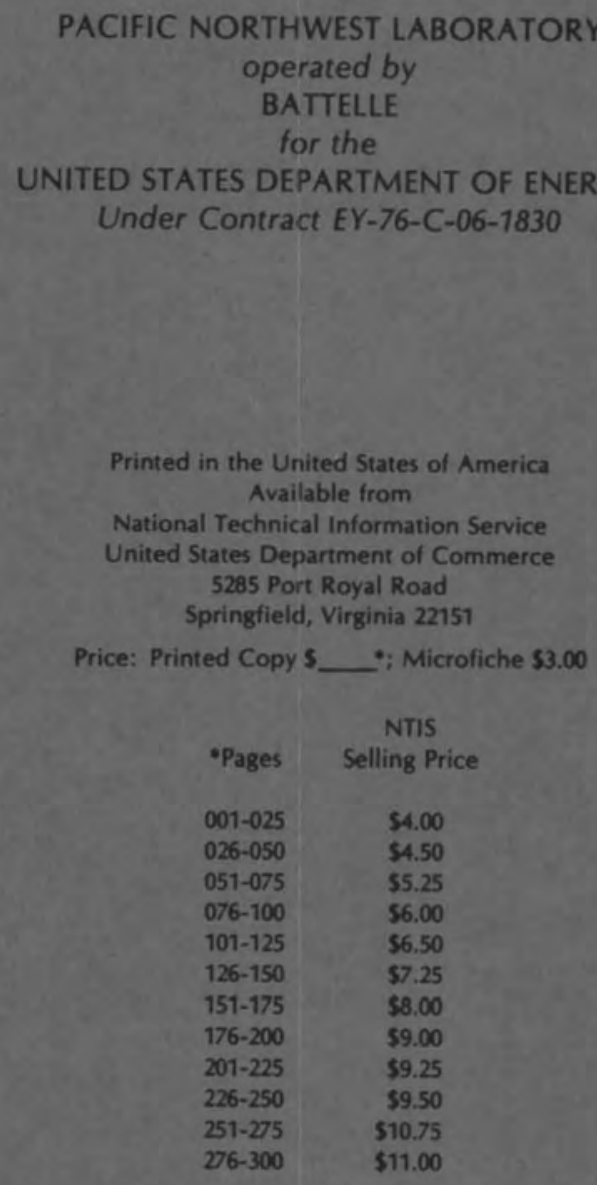


PNL -2867

UC-88

\section{AUTOMATED EXTRACTION SYSTEM}

DESIGN REVIEW
H. L. Parry
J. D. Eklund
J. M. Halter
R. G. Sullivan

March 1979

Prepared for the

U.S. Department of Energy

under Contract EY-76-C-06-1830

Pacific Northwest Laboratory

Richland, Washington 99352 


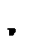




\section{CONTENTS}

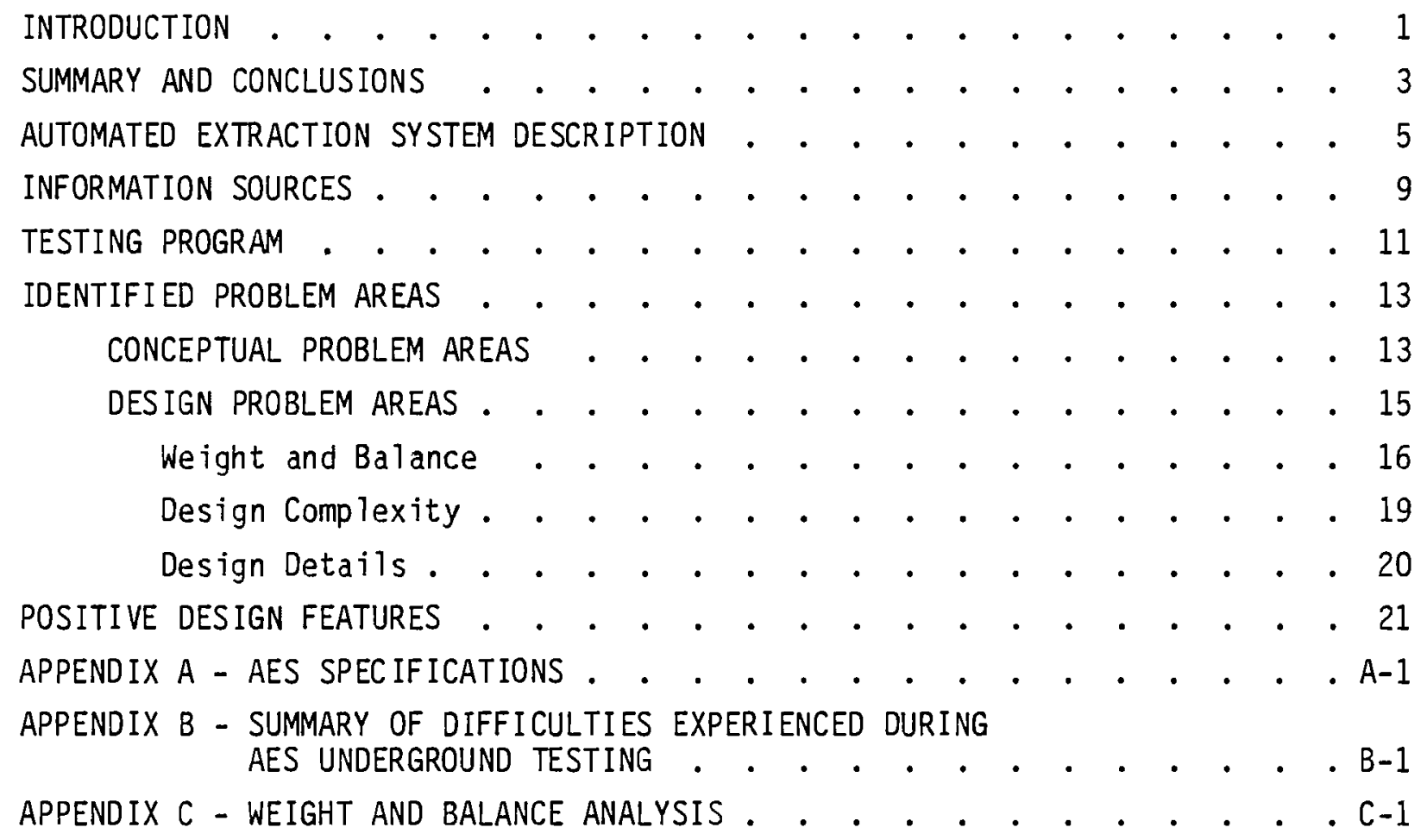





\title{
AUTOMATED EXTRACTION SYSTEM \\ DESIGN REVIEW
}

\author{
INTROOUCTION
}

The Automated Extraction System (AES) is an advanced fullface continuous mining system designed and built by National Mine Service Company, Nashville Division, under a contract with the U.S. Department of Energy (DOE). The AES incorporates advanced concepts in roof control, ventilation, and automated cycling, and is intended to be a prototype for a new generation of continuous miner. Initial AES testing in Consolidation Coal Company's Moundsville Operations McElroy Mine revealed operational problems in the machine; DOE is concerned about the cause of these problems. If the problems are due merely to the design and fabrication deficiencies typical of any advanced propotype, they can be remedied in a second-generation machine, However, if they are due to deficiencies in the basic machine concept, more serious system redesign may be needed. The Pacific Northwest Laboratory (PNL) was asked by DOE to review the AES design and operational experience to determine how serious the operational problems are and to suggest steps that should be taken in evaluating the design of a second-generation machine. This report reviews the problem areas observed during testing to identify areas needing attention in the second-generation machine design. The report also identifies areas in which more information is needed before a new design can be properly evaluated. 
- 


\section{SUMMARY AND CONCLUSIONS}

The AES design review was based primarily on information and observations gathered during a limited underground test program conducted prior to PNL's involvement in this review. The apparent goal of the test program was to evaluate production capability rather than to assess potential design problems and improvements. Consequently, although this review tried to take advantage of all test results available, it should be recognized that additional, as yet undiscovered, problem areas may exist.

PNL investigators divided the problem areas into two groups:

- problems caused by the basic AES concept

- problems caused by the mechanical design features used to carry out that concept.

Two potential conceptual problems were identified: the roof control concept and the hydraulic sumping concept. It is felt that the combination of uneven and cyclic roof loading found in the existing roof control system may promote roof failure, even in bolted roof areas. If this is true, major changes in the AES concept will be required. It is recommended that a test program aimed specifically at evaluating the roof loading problem be undertaken to verify the magnitude of this problem. The AES hydraulic sumping concept also must be reevaluated, as it appears that its ability to transfer sumping reaction loads to the floor may be concept limited. Both conceptual problem areas should be evaluated in detail before design and fabrication of a second-generation AES.

Critical design problem areas include those due to weight and balance, friction-induced excessive sumping forces, and design complexity. These are pointed out to identify areas where special attention should be placed should design begin in a second-generation AES. An analytical procedure that may be used to identify potential weight and balance problems during design is included in this report and identifies the causes of many of the operational problems experienced during the test program. In addition, the analysis shows the detrimental effect of high friction-induced resistance in the track units 
during sumping. The analysis also shows that the stinger modifications made during testing to overcome balance problems may detrimentally limit maximum sumping loads. Finally, the problem of machine complexity and maintainability is discussed. 


\section{AUTOMATED EXTRACTION SYSTEM DESCRIPTION}

The AES basic configuration is shown in Figures 1, 2, and 3. Machine specifications are given in Appendix A. The AES is based on a Marietta Drum Miner, manufactured by National Mine Service Company, using a retractable canted-end drum. Mining width is 15 feet; the drum contracts to 13 feet 4 inches for tramming. Four roof bolters spaced on 4-foot centers across the entry are mounted on the outer roof support system. The bolters are 19 feet 5 inches from the front of the cutter drum. The hydraulically actuated inner and outer roof support system is intended to temporarily support the roof adjacent to the bolters and forward toward the face. In addition, the outer roof support frame is used as a base to transmit sumping reaction loads to the floor and roof. Hydraulic sumping cylinders act between the outer support structure and the crawler-mounted drum assembly to provide the necessary sumping force.

The AES was designed to operate under worst-case roof conditions where the roof had to be continually supported. This would make the AES applicable to most of the thick seam mines operating in the United States. These universal requirements presented formidable design problems resulting in necessary compromises in the roof control system and bolter location. 


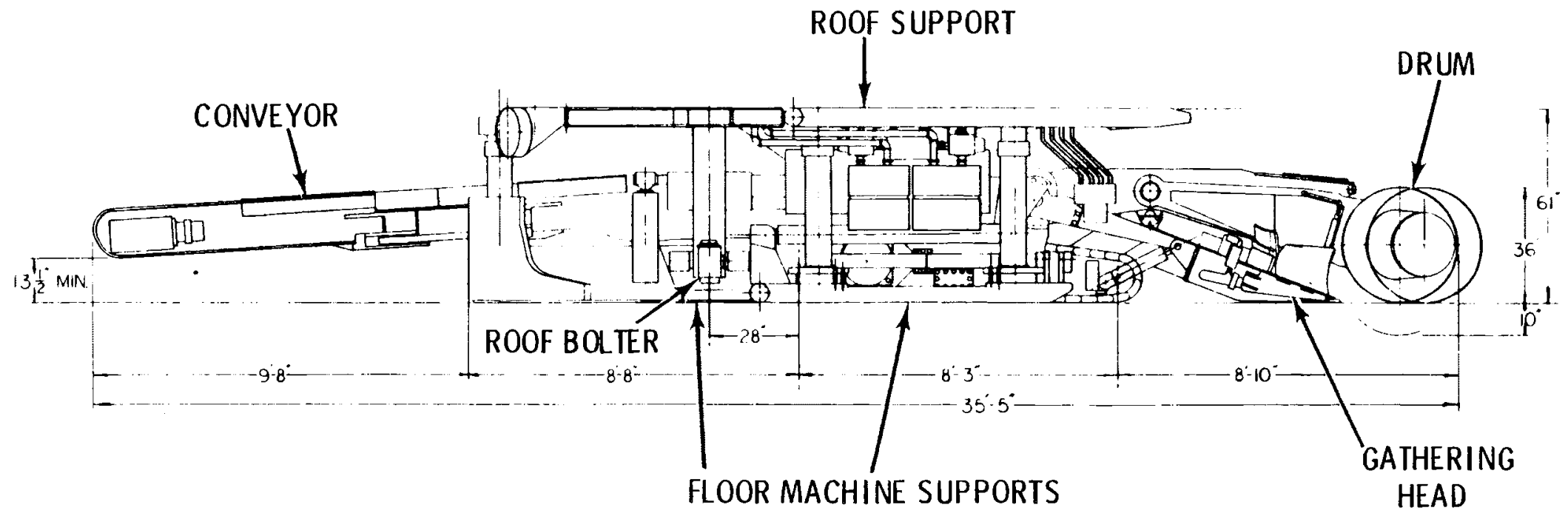

FIGURE 1. Side View of AES in Retracted Position 


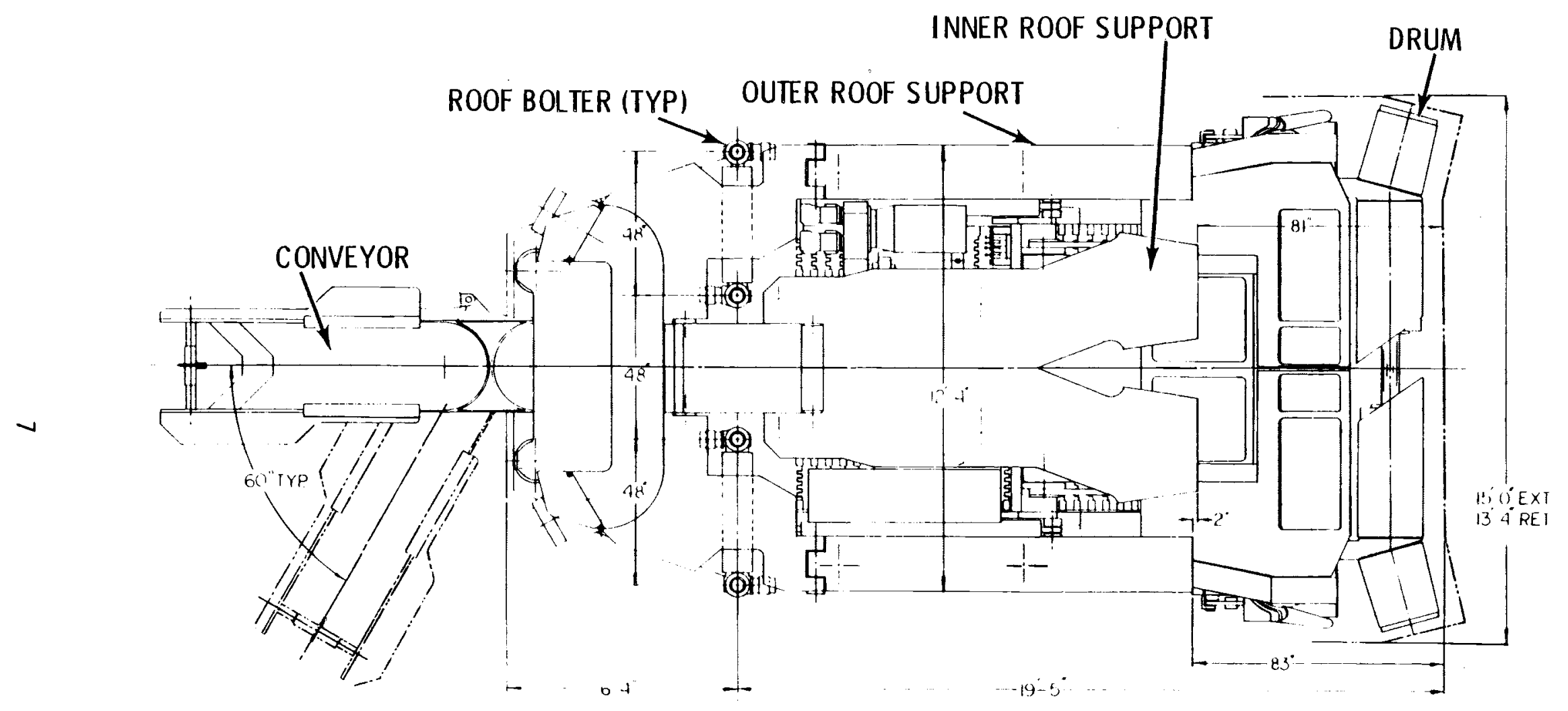

FIGURE 2. Top View of AES in Retracted Position 


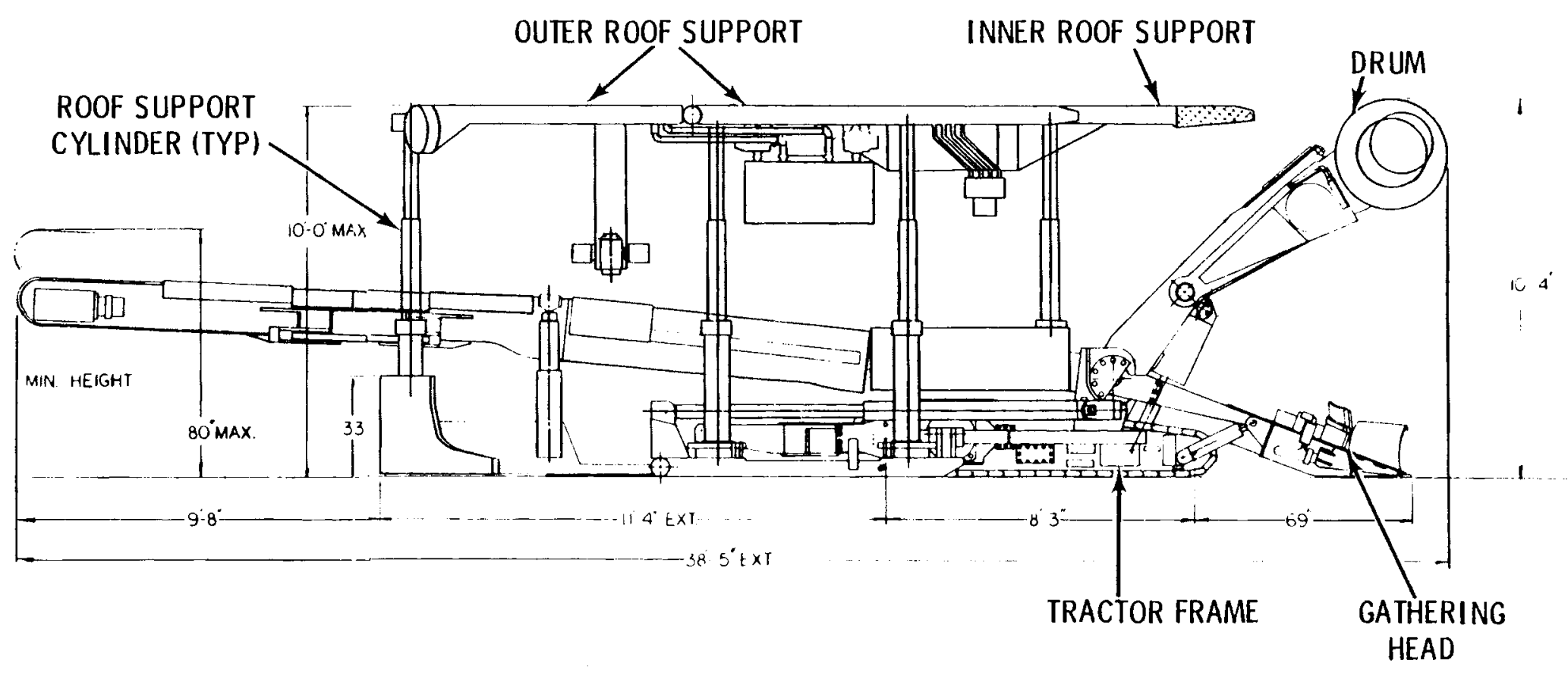

FIGURE 3. Side View of AES in the Fully Extended Position 


\section{INFORMATION SOURCES}

Pacific Northwest Laboratory personnel were not involved in AES design, fabrication or testing. The test program was suspended before the PNL design review began. Consequently, first-hand evaluation of the AES in operation has not been possible. The design review is based on the following input:

1. Inspection of the AES in the MCElroy mine shortly after test program suspension.

2. Onsite discussions with mine personnel involved in operating the machine during testing.

3. Discussions with National Mine Service (NMS) personnel involved in AES design and testing. Discussions were held both onsite and at the NMS Nashville, Illino is facility.

4. Discussions with the Department of Energy field engineer involved in the testing program.

5. Review of weekly and monthly test program progress reports written by Pennsylvania State University, College of Earth and Mineral Sciences, under DOE Contract ET-77-C-01-9144, "Performance Evaluation of Automatic Extraction System." These reports list operational problems encountered during testing. A summary of the operational problems can be found in Appendix B.

6. Review of the AES design drawings and specifications. 
$-$ 


\section{TESTING PROGRAM}

AES testing was limited to above-ground feature testing at National Mine Service Co. in Nashville, IL and underground demonstration in the McElroy Mine. This is the traditional way that new mining machines have been evaluated. In general, mining machinery development is a fairly slow evolutionary process; new machines have typically been based on design improvements to previous models. Because of the cautious evolutionary approach to developing new machines, a new machine could be expected to operate as planned, and testing was really a matter of demonstrating its abilities to the industry. However, the AES, which embodies many new concepts, is not the result of gradual evolution, but represents a major departure from a standard continuous miner. This is particularly true of the AES roof control system and the automated sumping system. A demonstration type of test program, based on the assumption that a prototype machine will operate as expected, may not be appropriate for a machine as complex as the AES. Testing of an entirely new prototype machine should evaluate not only potential production output, but, more importantly, the individual machine subsystems and concepts for future refinement (and for future machines). 'This sort of testing plan was initially instituted for the AES, but was not completed. When it became clear that the AES could not achieve significant production rates for any extended time, due mostly to roof control problems and reliability problems, the testing was suspended. Few, if any, evaluations aimed specifically at individual components or subsystems separated from production conditions were conducted. Consequently, evaluation of the existing design must be based on records of machine breakdowns during production testing and on conjecture. Because the actual operating time of the machine during the test program was under 200 hours, it should be stressed that undiscovered problem areas may still exist. 
, 


\section{IDENTIFIED PROBLEM AREAS}

Problem areas identified during testing and during review of the design were divided into two groups: conceptual problems and design problems. Conceptual problems relate to the basic approach of the AES toward the goal of mining coal. A verified conceptual problem might require complete redesign of the AES or its subsystems along totally different lines and thus constitutes a major area of concern. Design problems relate to the specific mechanical system used to carry out the AES concept. A design problem might be remedied by modifications to the existing system or by design changes prior to fabrication of a second-generation machine. Some design problems are inevitable in a new machine and are not as serious as a conceptual problem.

\section{CONCEPTUAL PROBLEM AREAS}

Review of the AES design and the operating experience during testing revealed two major potential conceptual problem areas--the roof support concept and the hydraulic sumping concept. It must be stressed that the 1 imited testing prevents verification of these items as consistent conceptual problems. Further evaluation of these systems should be completed before a second-generation machine is finalized.

The intended operating cycle of the roof support system is as follows: With the outer and rear roof support plates locked against the roof and the inner roof support lowered, the cutting head/inner roof support assembly is sumped forward by a preset distance of 12 to 30 inches, and the inner roof support is raised. The cutting drum then shears downward to the floor, and the inner roof support is lowered. The cutting head assembly is backed up to cut the cusp, raised into starting position and sumped forward to repeat the cycle. After the cutting drum has sumped forward a maximum of 5 feet, the inner roof support is locked in place against the roof. During the cutting cycle, roof bolts have been installed from the bolting stations on the outer roof supports. When bolting is 
completed and the inner roof supports are deployed, the outer and rear supports are lowered and pulled forward with the sumping cylinders. The outer and rear supports are then locked into place, the inner supports lowered and the entire cycle repeated.

During testing, roof failures occurred not only in the unbolted roof areas within the confines of the roof support area but also in previously bolted areas adjacent to the outer roof supports. Roof stability is known to be a problem in the test mine and it may well be that the failures experienced were due solely to the weak roof. However, consideration of the nature of loading placed on the roof by the roof support system brings up the possibility that the support system itself may promote roof failure.

Two roof loading conditions exist with the AES support system--nonuniform loading and cyclic loading. The roof support plates are rigid and cover a broad expanse of roof. Because of their rigidity they are unable to conform to inevitable irregularities in the roof surface. When the roof supports are pressed against the roof, protruding roof areas may become very highly loaded while recessed areas are not loaded at all. Localized fracturing may occur in the highly loaded areas even though the average roof loading is quite low. Such localized fracturing could promote roof failure. Combined with nonuniform loading is the cyclic roof loading caused by raising and lowering the roof supports as mining progresses. A given spot on the roof may be loaded and unloaded several times during the mining process. In a more conventional mining sequence, a roof area is loaded only during bolting and then only once. The AES cyclic loading may promote roof fracturing and possible roof failure.

If the roof support system is indeed promoting roof failure, the implications to the AES design are very serious. It may be possible to devise a flexible roof support pad to minimize nonuniform loading. However, avoiding the problem of cyclic loading may be more difficult. Elimination of the present roof support system would require major changes in the AES design. The existing system allows the roof bolters to be located back from the face. Eliminating the support system would require relocating the bolters closer to 
the face to maintain acceptably small areas of unsupported roof. Moreover, roof support system elimination would require a major change in the sumping system. Sumping is presently accomplished using hydraulic cylinders reacting against the outer roof support strucuture. Reaction forces are transmitted mostly to the floor through the locked roof supports and the floor machine supports. Elimination of the roof support system would require an alternative means of transmitting sumping loads to the ground.

More testing is needed to determine if the AES roof support system will indeed promote roof failure or if the observed failures were simply due to poor roof quality at the test mine. A test program to investigate the effects of cyclic and nonuniform loading on roof stability in different mines should be undertaken by DOE before fabricating a second-generation AES. If such a test program reveals that cyclic and nonuniform loads do indeed degrade roof strength, major changes in the AES concept will be needed.

The hydraulic sumping system concept was found to be limited due to the relatively small thrust available for sumping the cutting drum into the coal face. The hydraulic cylinders, which provide the sumping force, are anchored at one end to the stationary floor machine supports and attached at the other end to the track frame, forcing it and the cutting drum into the coal. Due to the high friction forces between the tracks and the track frame, and the limited amount of thrust the floor machine supports can withstand without slippage, the maximum force remaining for sumping is estimated to be 25,000 to 49,000 pounds. This force may not be sufficient for rapid coal removal. Therefore, provisions must be made in future machine designs to increase the available thrust. Details of the analysis used to determine the maximum thrust are contained in Appendix $C$.

\section{DESIGN PROBLEM AREAS}

Design problems are those which can be remedied by modifying the existing AES or during design of a second-generation machine. Design problems identified during testing fall into three categories--weight and balance, system complexity, and detail design. 
Weight and Balance

A static force and weight analysis was conducted on the AES to determine the weight distribution in various machine operating modes and the forces available to mine coal. Because detailed weight and force data was not available, a rigid body analys is was performed using assumptions based on the information available. The results indicate that some of the difficulties experienced by the AES when used in the mine were predictable.

It had originally been intended to investigate internal machine loads, particularly at machine joints, as part of this review. However, review of the difficulties encountered during testing indicated that evaluation of external loads and weight and balance problems would be of far greater benefit. Thus, internal joint loads were not investigated.

The analysis was performed in two areas. First, weight and system force distributions were analyzed in the tramming and sumping configurations. Second, the loads applied to the roof and floor and the resulting obtainable sumping thrust were determined. The details of the analysis, along with force and loading tables, appear in Appendix $c$. The results and conclusions are summarized in the following paragraphs.

The center of gravity for the AES while in the tramming configuration is located in the center of the tractor frame midway between the front and rear track axles. This is desirable, because it provides an even load distribution upon the floor. However, because the AES weighs approximately 155,000 pounds, the floor loading in the tramming configuration is approximately $43 \mathrm{psi}$. This high floor loading promotes floor surface degradation, particularly during AES maneuvering.

When the AES is in the sumping configuration, the location of the center of gravity becomes less desirable. Before the stinger modification (made during the test program to permit application of a downward force to the rear of the tractor frame) the center of gravity for the sumping portion of the AES. before pressure was applied to the sumping cylinders was 11 inches behind the forward track axle. However, when pressure was applied to the sump cylinders, the center of gravity shifted to 1 to 2 inches in front of the forward axle. 
As a result, when it was being sumped to the coal face, the sumping portion of the AES tended to lift the rear portion of the tractor frame off the floor, resulting in floor loadings in the front axle area of up to 110 psi. This excessive floor pressure allowed the tracks to dig into the floor and effectively created an additional resistive barrier for the tracks to overcome when sumped further. In addition, the lifting of the rear of the tractor frame and subsequent depression of the front caused the sumping cylinder shafts to bend due to mechanical interference.

During sumping to the face, the center of gravity shifted forward of the front axle. This was primarily due to an overturning moment caused by friction forces that had to be overcome. The primary friction force was due to the steel-on-steel contact between the track frame and the track shoes. Coupled with the force required to back drive the electric motors and reduction gearing, this friction force resulted in approximately 57,000 pounds of sumping cylinder thrust needed just to move the sumping portion of the AES forward without mining coal. In addition, approximately 2,000 pounds of thrust were required to push the gathering head along the floor due to friction between the front edge of the head and the floor. (This assumes a level floor without discontinuities for the leading edge to catch upon.) Consequently, a sumping thrust of up to 59,000 pounds is needed to overcome just the frictional forces, thus reducing the thrust available for mining coal.

When the AES is removing coal, the center of gravity shifts toward the center of the track frame due to the upward force caused by the rotating drum as it chisels out the coal. Although this helps to reduce the tendency for the front part of the tracks to dig into and damage the floor, damage does occur when the AES is moving to the face and backing up to cut the remaining cusp.

Part way through the underground test program, the AES was modified to permit a downward force to be applied on the stinger at the rear of the tractor frame (see Figures $\mathrm{C}-4$ and $\mathrm{C}-10$ in Appendix C for stinger location), thus preventing the front of the tracks from digging into the floor. This 
modification helped move the center of gravity of the AES sumping portion rearward by an amount dependent on the downward force applied. The modification helped redistribute the track loading, effectively moving the center of gravity up to 39 inches rearward of the front track axles, at the expense of increasing the total loading on the tracks by the amount of force applied. Overall, the load redistribution proved beneficial by holding the rear of the tractor frame down, thereby preventing the front of the tracks from digging into the floor during sumping and preventing mechanical interference with the sump cylinder shafts. However, the increased total floor loading caused by the modification makes it a compromise solution. The only real solution to the weight and balance problem is AES redesign with careful attention to minimizing system weight and rearranging components for better balance.

The roof support system provided two capabilities to the AES system. It provided temporary roof support until roof bolts could be inserted by the automated bolters. More importantly, it provided an anchor from which the AES sumping portion could be hydraulically sumped forward into the coal. Due to the nonrigid coupling between the roof supports and the floor machine supports, the thrust was due almost totally to the friction between the floor elements and the gound. If the hydraulic pressure in the roof support cylinders is $1000 \mathrm{psi}$ (the maximum pressure used in the mine tests) and the coefficient of friction between the lower supports and the ground is $0.6(\mu=$ 0.6 is felt to be the maximum for a Caterpillar type track and a coal mine floor) the maximum obtainable thrust is approximately 107,460 pounds. With maximum stinger force, this reduces to 83,820 pounds (see Table $C-7$, Appendix C). When it is considered that 59,000 pounds are required to overcome friction within the AES, 25,000 pounds (with stinger) to 49,000 pounds (without the stinger modification) represents the maximum force remaining to sump into the coal. Thus, the stinger modification actually reduces the available sumping force.

\footnotetext{
Trademark of the Caterpillar Tractor Company, Peoria, IL.
} 


\section{Design Complexity}

Many of the reliability problems experienced during onsite testing were due to the complexity of the AES. The AES is basically a drum miner, roof support system and four bolters combined into one crowded complex machine with a number of reliability problems. The number of components alone, each with its own reliability, serves to reduce overall system reliability. This is particularly true of the hydraulic system, with its large number of components and myriad connecting hoses. The machine consists of several major elements, each capable of moving with respect to each other. A large variety of component positions are possible during the machine operating cycle. Interference problems have been encountered as machine components moved relative to each other in ways perhaps not envisioned by the designer. The result has been sheared hydraulic hose, bent sumping cylinders and loosened hydraulic fittings. Such interference problems have combined with the extreme difficulty of gaining maintenance access to components and fittings buried in a crowd of hydraulic hoses or machine parts to make system maintenance a very time-consuming process. This is particularly true underground, where the size of the machine alone restricts access. Moreover, although insufficient operating experience was gained during testing to evaluate machine/operator interface, it is conceivable the crowded nature of the machine may also cause operator visibility problems during mining.

It should be recognized that the AES is a first prototype. Interference, maintenance and reliability problems are not unusual in an entirely new machine. However, it is recommended that the design of a second-generation machine minimize these problems. Extra time spent in designing the hydraulic layout to minimize hoses and fittings and to improve maintenance access will be well worth it. Careful attention should be paid to possible interference problems during design.

In addition to careful design, an extensive above-ground test program should be undertaken to help identify potential problems in all machine operating modes. The machine should be run through enough operating cycles under different conditions to insure that such things as interference problems 
and leaking fittings are identified and alleviated before going underground. Repairs and modifications underground are difficult, time-consuming and expensive, and could be minimized by extensive above-ground testing.

\section{Design Details}

Detail design problems are those which, in themselves, are fairly minor, requiring minimal machine modification to alleviate. These problems are often not discovered until testing begins and provide another good reason for extensive above-ground testing before going underground. While detail design problems in themselves may not be serious, their solution can be timeconsuming. This is particularly true when repairs must be accomplished underground. Identified detail design problems on the AES include:

1. mechanical interference in the gathering heads, resulting in several gathering head motor failures - This problem has apparently been eliminated by modifications made during the test program.

2. inadequate mechanical overload protection for hydraulic cylinders subjected to side loads - Modifications during the test program eliminated this problem in the sump cylinders, but it remains a potential problem for the roof support cylinders. Failure of lower roof support cylinder end fittings due to excessive side loads occurred just before the test program was suspended.

3. Hydraulic system leakage - Leakage from hydraulic fittings was a continual problem during the test program. Field repair of leaks was greatly hampered by poor maintenance access.

While careful design can minimize problems such as those listed above, some detail anomalies will be inevitable in a new prototype machine. However, a thorough above-ground test program can identify such problems so that they can be eliminated before the machine is taken underground. 


\section{POSITIVE DESIGN FEATURES}

By concept, the AES was intended to operate by automatic controls. While they were only used for approximately one shift, the automatic controls operated reliably with few problems experienced and indicated a potential future for automation underground. The system was easily programmed for various mining cycles and worked on demand.

Two additional features of the AES design, the ventilation system and the lighting system, were praised by all those involved in the underground operation of the machine. The ventilation system provided for inlet openings in the inner roof support beams approximately 7 feet from the face. Contaminated air pulled in through these inlets could be exhausted by hydraulically driven fans through flexible blow-up tubing into the mine returns. This ventilation system was quite effective in maintaining an acceptable operator environment. The ventilation system's only drawback was that the vent fans could not be operated independently of the machine's main hydraulic system. Consequently, ventilation could not be maintained whenever the main hydraulic system was being modified or repaired. This is a small design deficiency easily eliminated in a second-generation design. The AES lighting system was praised for providing full lighting of the entire area of operation as well as of the mining face. 

APPENDIX A

AES SPECIFICATIONS 
APPENDIX A

AES SPECIFICATIONS(a)

Machine Envelope Dimensions

Overa11 Machine Length

Cutting Head Width

Mining

Retracted

Machine Width Outside Roof

and Floor Beams

Weight

Face Area

Coal/ft Advance

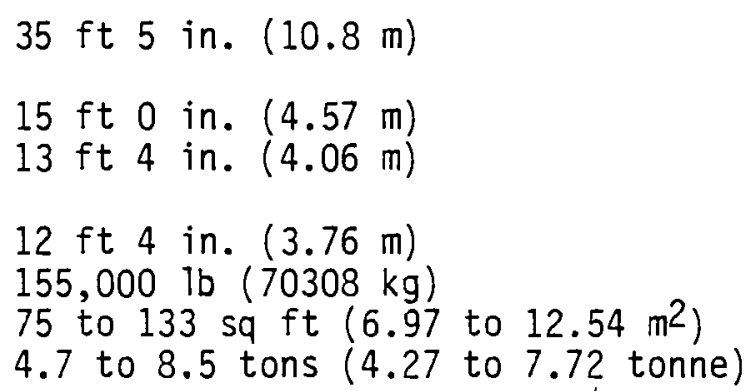

$35 \mathrm{ft} 5$ in. $(10.8 \mathrm{~m})$

$15 \mathrm{ft} 0$ in. $(4.57 \mathrm{~m})$

$13 \mathrm{ft} 4$ in. $(4.06 \mathrm{~m})$

$12 \mathrm{ft} 4$ in. $(3.76 \mathrm{~m})$

$155,000 \mathrm{lb}(70308 \mathrm{~kg})$

75 to $133 \mathrm{sq} \mathrm{ft}\left(6.97\right.$ to $\left.12.54 \mathrm{~m}^{2}\right)$

4.7 to 8.5 tons ( 4.27 to 7.72 tonne)

Tractor Frame

Ground Clearance

Tracks

Type

Width

Ground Contact Length

Area

Ground Pressure (Max. Tramming)

Tram Drive

Type .

Maximum Belt Pull

Speed

Motor (Two Water Cooled)

6 in. $(15.24 \mathrm{~cm})$

Piano Hinge

18 in. $(45.72 \mathrm{~cm})$

99 in. Nominal $(251.46 \mathrm{~cm})$

$3564 \mathrm{sq}$ in. (22993.5 $\left.\mathrm{cm}^{2}\right)$

43 psi (2.96 Bar)

Spur Primary Two Stage PTanetary

Fina 1

$50,000 \mathrm{lb} / \mathrm{side}(22680 \mathrm{~kg} / \mathrm{side})$

$13.3 \mathrm{ft} / \mathrm{min}-40 \mathrm{ft} / \mathrm{min}$ (4.05-12.19 m/min)

$7.5 \mathrm{hp} 0600 \mathrm{rpm}(5.59 \mathrm{~kW})$

$30 \mathrm{hp}$ a $1800 \mathrm{rpm}(22.37 \mathrm{~kW})$

Cutter Drum

Drum Outside Diameter

Base Diameter

Cutter Boom Height

Drum on Grade

Above Grade

Cutter Drum Reach

Below Grade (Max.)

With Gathering Head on Grade

36 in. $(91.44 \mathrm{~cm})$

22 in. $(55.88 \mathrm{~cm})$

42 in. $(106.68 \mathrm{~cm})$

$10 \mathrm{ft} 0$ in. $(3.05 \mathrm{~m})$

10 in. $(25.4 \mathrm{~cm})$

5 in. $(12.7 \mathrm{~cm})$

(a) Data were taken from Donald L. Freed, Jr., "Safety Aspects of the AES (Automated Extraction System)," Society of Mining Engineers of AIME, Reprint Number 78-F-50, February 1978. 
Cutter Drum Drive

Motors (Two Water-Cooled)

Drum Speed

Drive Type (2)

Bit Speed

Protection - Clutches (2)

Gathering Head

Type

Gathering Head Width

Mining

Retracted

Disc Sizes Large Sma 11

Disc rpm Large Sma 11

Drive Motors (Two Water-Cooled)

Conveyor

Width

Depth (Steel Sideborads)

Sideboards (Flexible)

Chain

Drive

Speed

Loading Rate (Max. with 5 in depth)

Tensioning

Swing Angle

Roof Support/Operator Protection System

Type

Support Cylinder

Quant ity

Bore L

Rated Pressure

Capacity at Rated Pressure

Roof Beams - Outer

Quantity

Width

Length

Approximate Roof Area

Average Roof Pressure at

Cylinder Capacity
$200 \mathrm{hp} \mathrm{ea.} 1200 \mathrm{rpm}(150 \mathrm{~kW})$

$57 \mathrm{rpm}$ (63 and 70 optional)

Beve 1 and Planetary

$535 \mathrm{fpm}$ (595, 660 optional)

(163m/min $(181,201$ optional)

Multi Disc, $600 \mathrm{hp} \mathrm{STip}(450 \mathrm{~kW})$

Disc

$15 \mathrm{ft} 0$ in. to $16 \mathrm{ft} 0$ in. $(4.57$

to $4.88 \mathrm{~m}$ )

$14 \mathrm{ft} 0$ in. $(4.27 \mathrm{~m})$

$4 \mathrm{ft} 5$ in. $(1.35 \mathrm{~m})$

$2 \mathrm{ft} 6$ in. $(.76 \mathrm{~m})$

70

117

$15 \mathrm{hp}$ ea (o $1750 \mathrm{rpm}(11.2 \mathrm{~kW})$

30 in. $(76.2 \mathrm{~cm})$

5 in. $(12.7 \mathrm{~cm})$

4 in. $(10.2 \mathrm{~cm})$

2 5/8-in. Pitch Redbird $(6.67 \mathrm{~cm})$

Rear Hydraulic

$400 \mathrm{ft} / \mathrm{min}(121 \mathrm{~m} / \mathrm{min})$

$11.6 \mathrm{~T} / \mathrm{min}$ (10.53 tonne/min)

Automatic Load Sensitive Hydraulic $60^{\circ}$ Left or Right

Longitudinal Roof and Floor Beam

10

7 in. $(17.78 \mathrm{~cm}), 5.5$ in. inner cylinder

3000 psi (206.8 Bar)

35.6 tons each (32.32 tonne)

2

18 in. each $(45.72 \mathrm{~cm})$

$10 \mathrm{ft} 4 \mathrm{in}$. each $(3.15 \mathrm{~m})$

4464 in. 2 (both)

63.8 psi (4.40 Bar) 


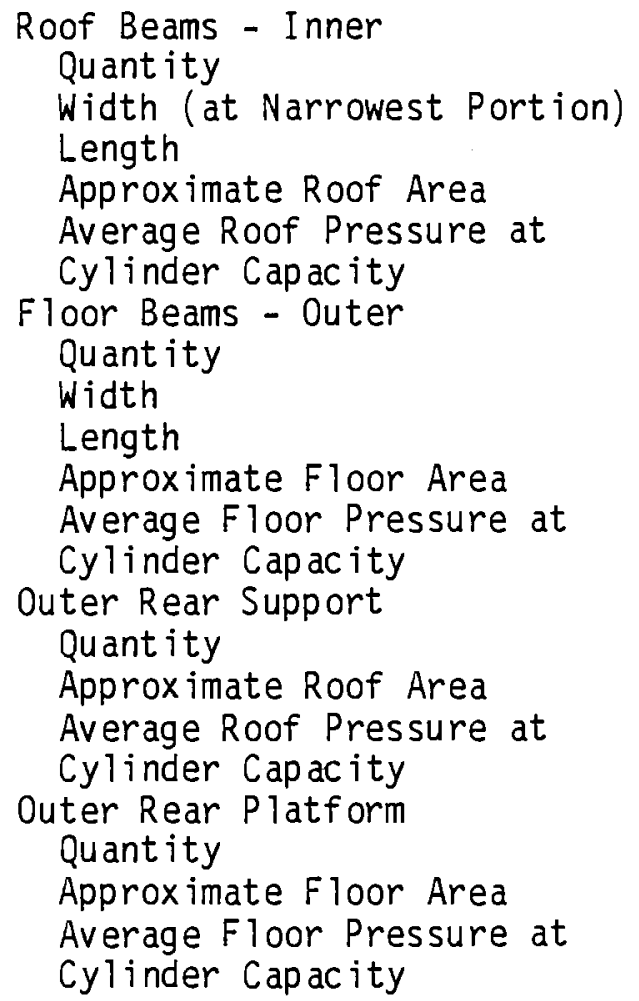

Low Range Support System

Minimum Tram Height

Outer Floor Beam Ground Clearance

Mining Range (With 12 in. Tram

Top Clearance)

High Range Support System

Minimum Tram Height

Outer Floor Beam Ground Clearance

Mining Range (With 12 in. Tram

Top Clearance)

Pump Drive

Motor (One Water-Cooled

Pumps

Drills (4)

Scrubbers (1)

Cylinders (1)

Vent Fans (1)

Conveyor (1)

Water (1)

Gear Box

Reservior Capacity
1

5 ft 0 in. $(1.52 \mathrm{~m})$

$11 \mathrm{ft} 9$ in. $(3.56 \mathrm{~m})$

8460 in. 2

33.64 psi (2.32 Bar)

2

18 in. each $(38.1 \mathrm{~cm})$

$971 / 4$ in. each $(247 \mathrm{~cm})$

3500 in. $^{2}$ (both)

81.3 psi (5.61 Bar)

1

$4,050 \mathrm{sq}$. in. $\left(26,128 \mathrm{~cm}^{2}\right)$

35.2 psi (2.43 Bar)

1

$4,080 \mathrm{sq}$. in. $\left(26,323 \mathrm{~cm}^{2}\right)$

34.9 psi (2.41 Bar)

51 in. $(129.54 \mathrm{~cm})$

$41 / 4$ in. $(10.8 \mathrm{~cm})$

$5 \mathrm{ft} 0$ in. to $7 \mathrm{ft} 4 \mathrm{in}$.

(1.52 to $2.24 \mathrm{~m}$ )

$5 \mathrm{ft} 1$ in. $(1.55 \mathrm{~m})$

6 in. $(15.24 \mathrm{~cm})$

$6 \mathrm{ft} 1$ in. to $10 \mathrm{ft} 0$ in.

( 1.85 to $3.05 \mathrm{~m}$ )

$200 \mathrm{hp} 1200 \mathrm{rpm}(150 \mathrm{~kW})$

30 gpm Gear (113.5 $\ell / m i n)$

$30 \mathrm{gpm}$ Gear (113.5 $\ell / \mathrm{min})$

$0-37.6 \mathrm{gpm}$ VV Piston (142.3 $\ell / \mathrm{min})$

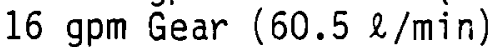

$30 \mathrm{gpm}$ Gear (113.5 $\ell / \mathrm{min})$

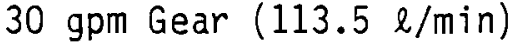

Spur Gear Water-Cooled 200 gal (757 \&) 
Roof Drills

Quantity

Feed Rate - Maximum

Torque Maximum

Bolt Torque

Thrust - Maximum

Thrust - Torquing

Location

4

$25 \mathrm{ft} / \mathrm{min}(7.92 \mathrm{~m} / \mathrm{min})$

300 lb-ft (406 newton-m)

250 1tb-ft ( 340 newton-m)

$8000 \mathrm{lb}(35,600$ newton $)$

$2001 \mathrm{~b}$ (890 newton)

$2 \mathrm{ft} 0 \mathrm{in}$. and $6 \mathrm{ft}$ either side of center line $(0.61$ and $1.83 \mathrm{~m})$

Roof Drill Dust Collection Blowers

Quantity

Type

$60 \mathrm{cfm} \mathrm{co} 12 \mathrm{in} . \mathrm{Hg} \cdot\left(1.7 \mathrm{~m}^{3} / \mathrm{min}\right.$ (a $30.48 \mathrm{~m} \mathrm{Hg}$.)

4

Positive Displacement - 2 Rotor Lobe Type

Collectors

Quantity

Type

4--1 Per Drill

3 Stage--2 Centrifugal, 1 Media Type Filter

Manuf acturer

Donaldson

Ventilation Fans

Quantity

Type

2

Capacity Each

Axial Flow

$3000 \mathrm{cfm} @ 12$ in. $\mathrm{H}_{2} \mathrm{O}$

$\left(84.96 \mathrm{~m}^{3} / \mathrm{min}\right)$

Air Scrubbers

Quantity

Type

Manufacturer

Capacity

Water Requirement

2

Centrifuga 1, Wet Impingment

T. J. Gund lach

$2000 \mathrm{cfm}$ each $\left(56.64 \mathrm{~m}^{3} / \mathrm{min}\right)$

1 - $2 \mathrm{gpm}$ each $(3.8-11.4 \mathrm{l} / \mathrm{min})$

Mining Cycle

Set-Up (Manual Operation)

Unlock and pull up outer supports and bumper, make any necessary machine position corrections, raise and lock roof supports.

Automatic Cycle - Coal (Two, Three, Four, or Five Sumps/Outer Support Move)

Unlock inner roof support, sump, lock inner roof support, shear, unlock inner roof support, back up and cut cusp, raise drum to roof, move back to face, sump, lock inner roof support, shear, unlock inner roof support, back up and cut cusp, raise drum to roof, move back to face, lock inner roof support, wait for operator's consent, unlock and move outer support forward, lock outer support. Repeat at operator's discretion. 
Automatic Cycle - Slate (Two, Three, Four, or Five Sumps/Outer Support Move)

Unlock inner roof support, sump under slate, lock inner roof support, shear, unlock inner roof support, back up and cut cusp, raise drum to roof, sump, lock inner roof support, shear until below slate, unlock inner roof support, back up and cut cusp, raise drum to roof, sump, lock inner roof support, shear until below slate, wait for operator's consent, unlock and move outer support forward, lock outer support. Repeat at operator's discretion.

\section{Additional Features}

Water deluge fire suppression system

Approved lighting, face and area

High visibility paint

Compatible with invert emulsion fire resistant hydraulic fluids

High efficiency filtration is provided on return flow before entering tank. All replacement $0 i 1$ is filtered before entering tank. Pilot circuit utilizes high pressure filtration.

Improved face water spray system. 
APPENDIX B

SUMMARY OF DIFFICULTIES EXPERIENCED

DURING AES UNDERGROUND TESTING

$8 / 29 / 77-4 / 27 / 78$ 
APPENDIX B

SUMMARY OF DIFFICULTIES EXPERIENCED DURING

AES UNDERGROUND TESTING, 8/29/66 - 4/26/78

The following information was summarized from week ly reports submitted by Pennsylvania State University to DOE under Contract ET-77-C-01-9144, "Performance Evaluation of Automatic Extraction System."

DATE

\section{DIFFICULTY}

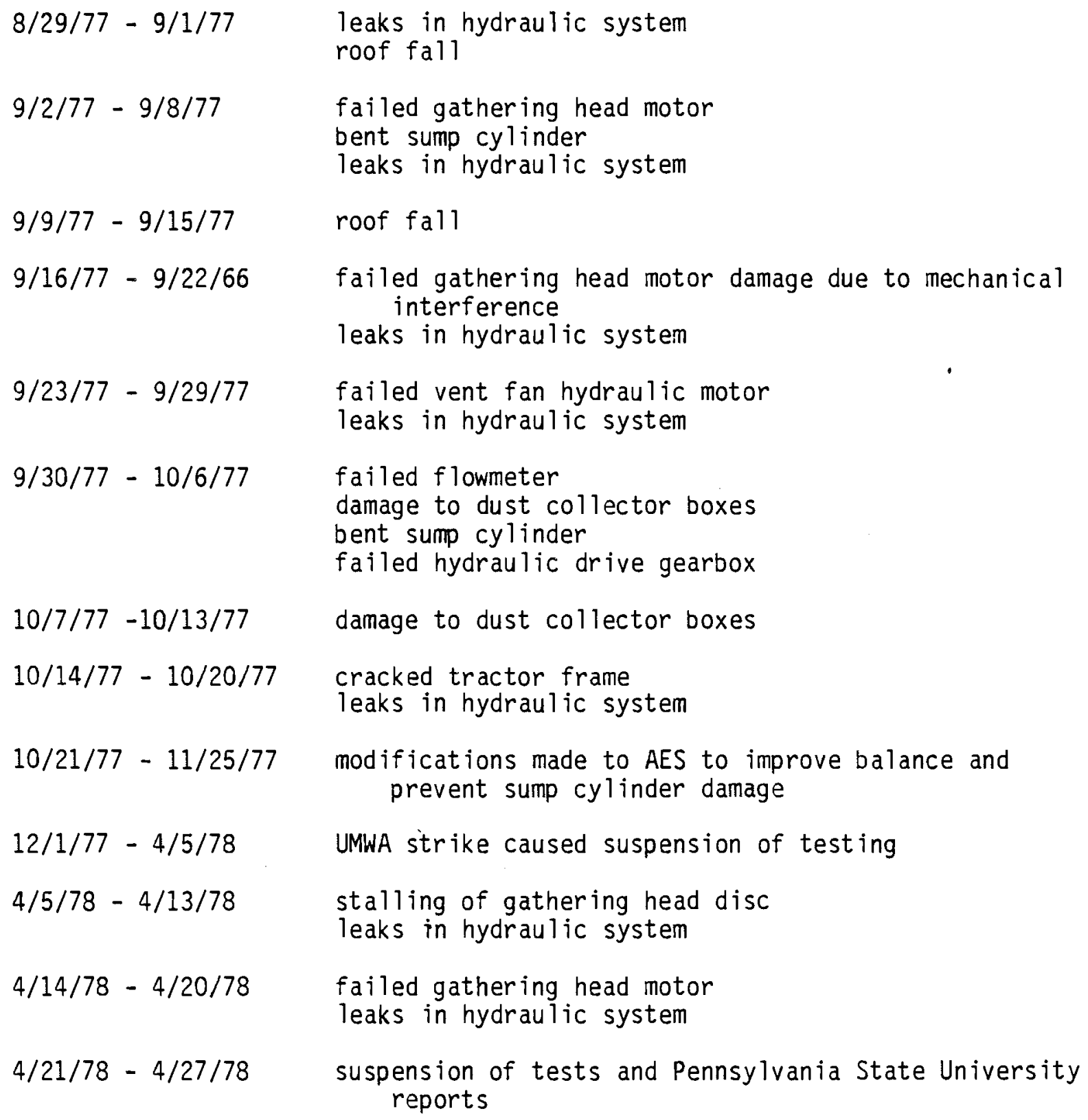


APPENDIX C

WEIGHT AND BALANCE ANALYSIS 
APPENDIX C

WEIGHT AND BALANCE ANALYSIS

\section{WEIGHT AND CENTER OF GRAVITY DETERMINATION}

The AES, illustrated in Figures 1 and 3 in the tramming and working positions, respectively, was divided into seven major subassemblies so that the weight distribution could be more easily determined. The machine components, weights and centers of gravity were estimated based upon the quantity and distribution of the steel used in fabrication and component group shipping weights, which were determined when they were transported from the manufacturing facility to the mine. The components are illustrated in Figures C-1 through $\mathrm{C}-7$ with their weights and centers of gravity noted. Table $\mathrm{C}-1$ contains the components' estimated weights and the shipping weights for groups of components.

The major components were grouped into two major assemblies--the sumping portion, which contains the tracks, gathering head and cutting drum; and the stationary rear portion, which contains the operator platform, roof drills and conveyor and provides an anchoring location from which the sumping portion can push itself forward. The center of gravity and weight were then determined by summing forces and moments. Figures $\mathrm{C}-8$ through $\mathrm{C}-10$ show the location and magnitude determined for the rear and sumping portions in two separate configurations--gathering head raised and gathering head floating upon the ground, respectively. Table $\mathrm{C}$-2 lists the data used to obtain the center of gravity.

As can be seen, the center of gravity for the sumping position varies between 6 and 11 inches from the front track axle, depending on whether the gathering head is raised or floating upon the ground. Therefore, without the modifications later made to the stinger, $(a)$ the sumping portion would tend

(a) The stinger was modified so that force could be transferred to the tractor portion of the AES from the stationary rear portion when sumping was taking place. Pins in the stinger, which is attached to the back of the tractor frame, slide in a track located on the operator platform. When force is applied to the stinger by hydraulic cylinders in an attempt to raise it, force is applied to the back of the tractor frame, effectively transferring the center of gravity toward the rear. 


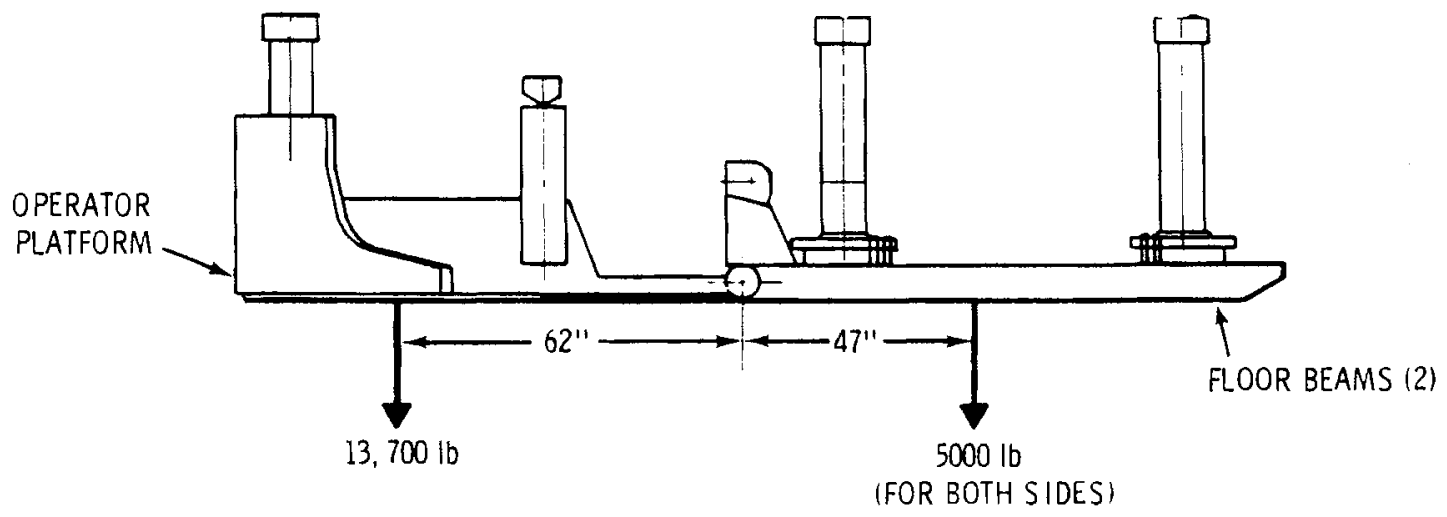

FIGURE C-1. Floor Machine Supports Center of Gravity

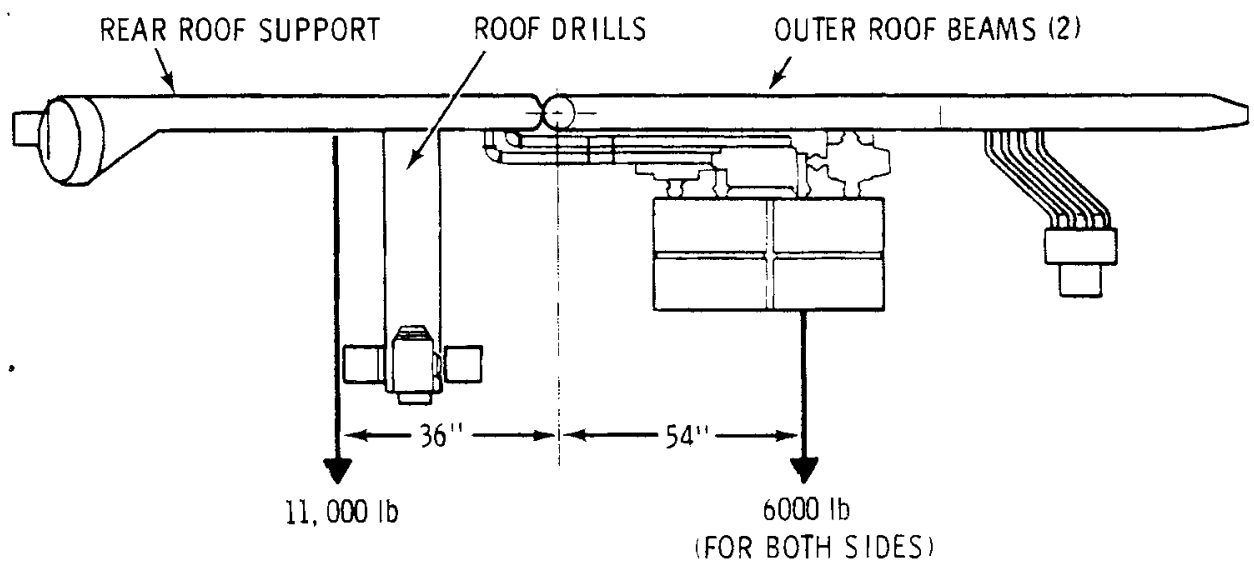

FIGURE C-2. Roof Supports Center of Gravity 


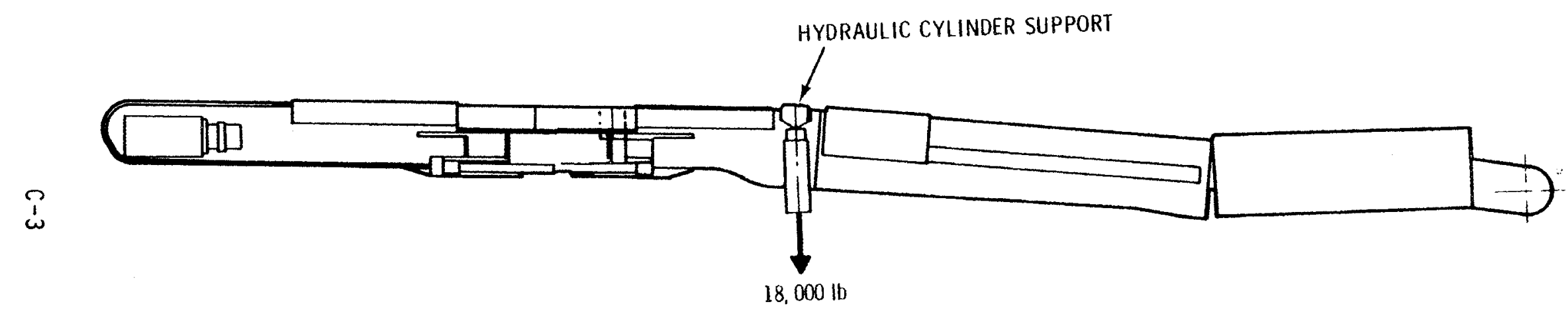

FIGURE C-3. Conveyor Center of Gravity 


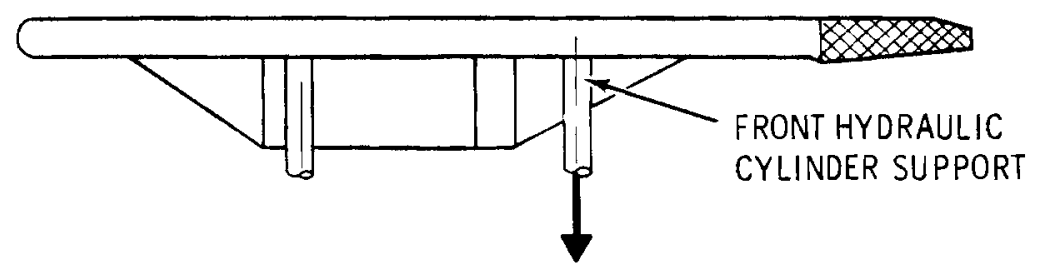

$11,100 \mathrm{lb}$

FIGURE C-4. Inner Roof Support Center of Gravity

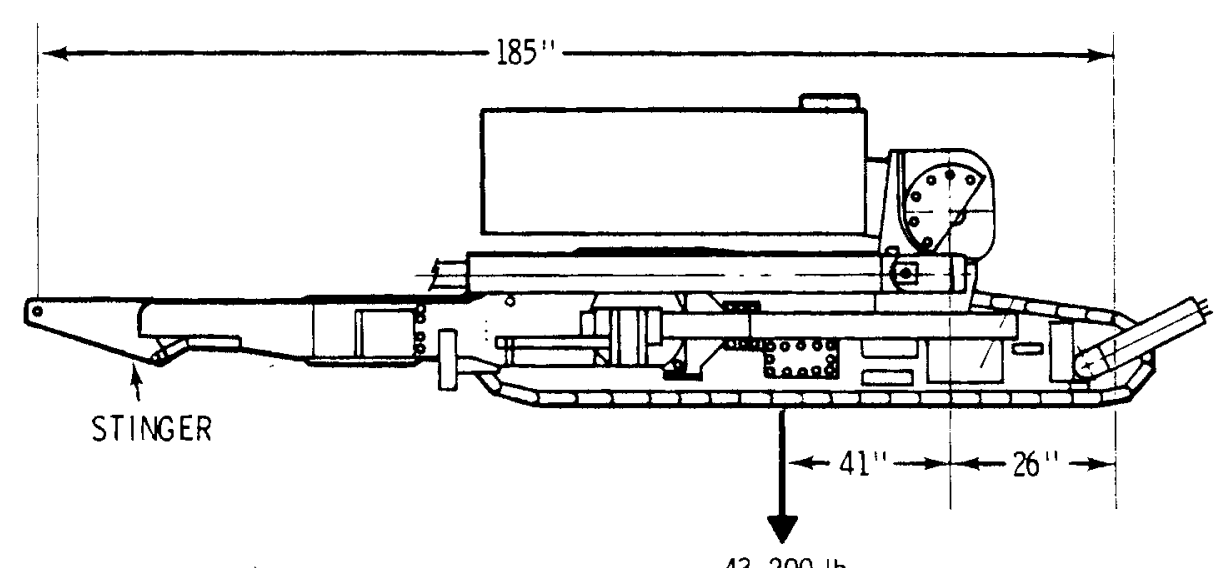

$43,200 \mathrm{lb}$

FIGURE C-5. Tractor Frame Center of Gravity 


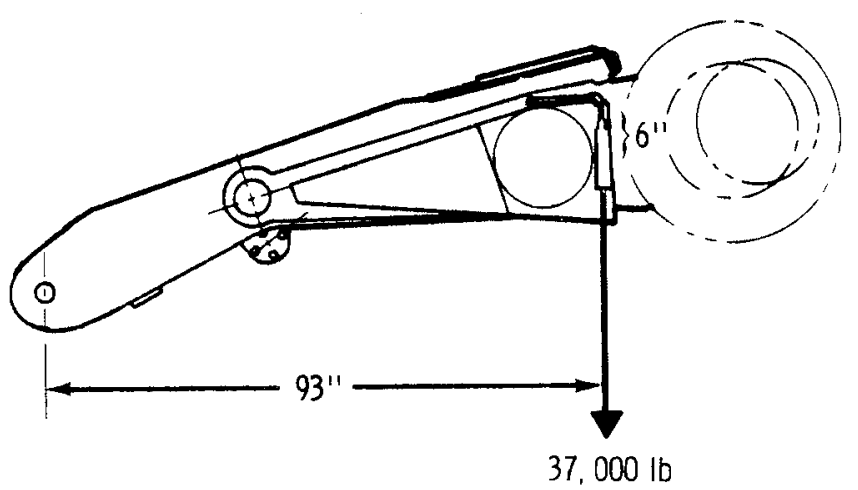

FIGURE C-6. Cutter Boom Center of Gravity

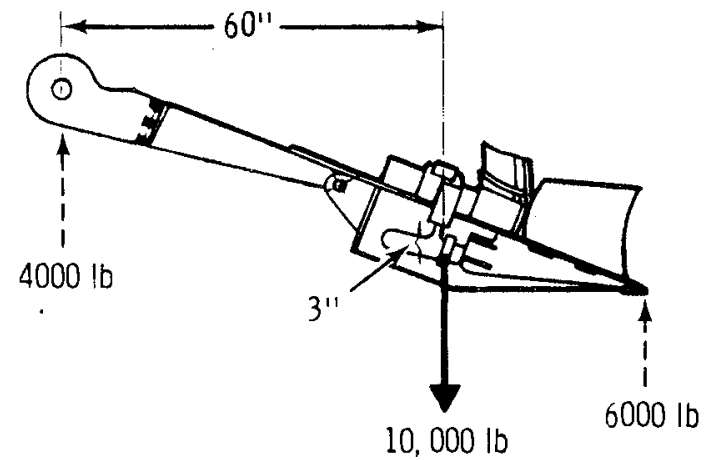

FIGURE C-7. Gathering Head Center of Gravity

$$
C-5
$$


TABLE C-1. AES Component Estimated and Shipping Weights

\begin{tabular}{|c|c|c|}
\hline \multirow{2}{*}{ AES Components } & \multirow{2}{*}{$\begin{array}{c}\text { Estimated Weight } \\
\mathrm{Ib} \\
\end{array}$} & \multirow{2}{*}{$\begin{array}{r}\text { Shipping Weigh } \\
\text { Ib } \\
\end{array}$} \\
\hline & & \\
\hline Cutter boom structure and & & \\
\hline drum drive assembly motors & 37000 & \\
\hline Rear roof support & 5000 & \\
\hline Roof drills & 6000 & \\
\hline GROUP TOTAL & & 48080 \\
\hline Inner roof support & $8100+3000^{(a)}$ & \\
\hline Rear operators platform & 13700 & \\
\hline Outer roof beams (2) & $4000+2000^{(a)}$ & \\
\hline Floor beams (2) & 5000 & \\
\hline Misc. Components & $1300^{(b)}$ & \\
\hline GROUP TOTAL & & 32240 \\
\hline Track frame assembly with pump & & \\
\hline and inner roof cylinders & 43200 & 43200 \\
\hline Conveyor & 18000 & \\
\hline Gathering head assemb ly & 10000 & \\
\hline Separate misc. components & $3140^{(b)}$ & \\
\hline GROUP TOTAL & & 31480 \\
\hline & TOTAL & 155,000 \\
\hline
\end{tabular}




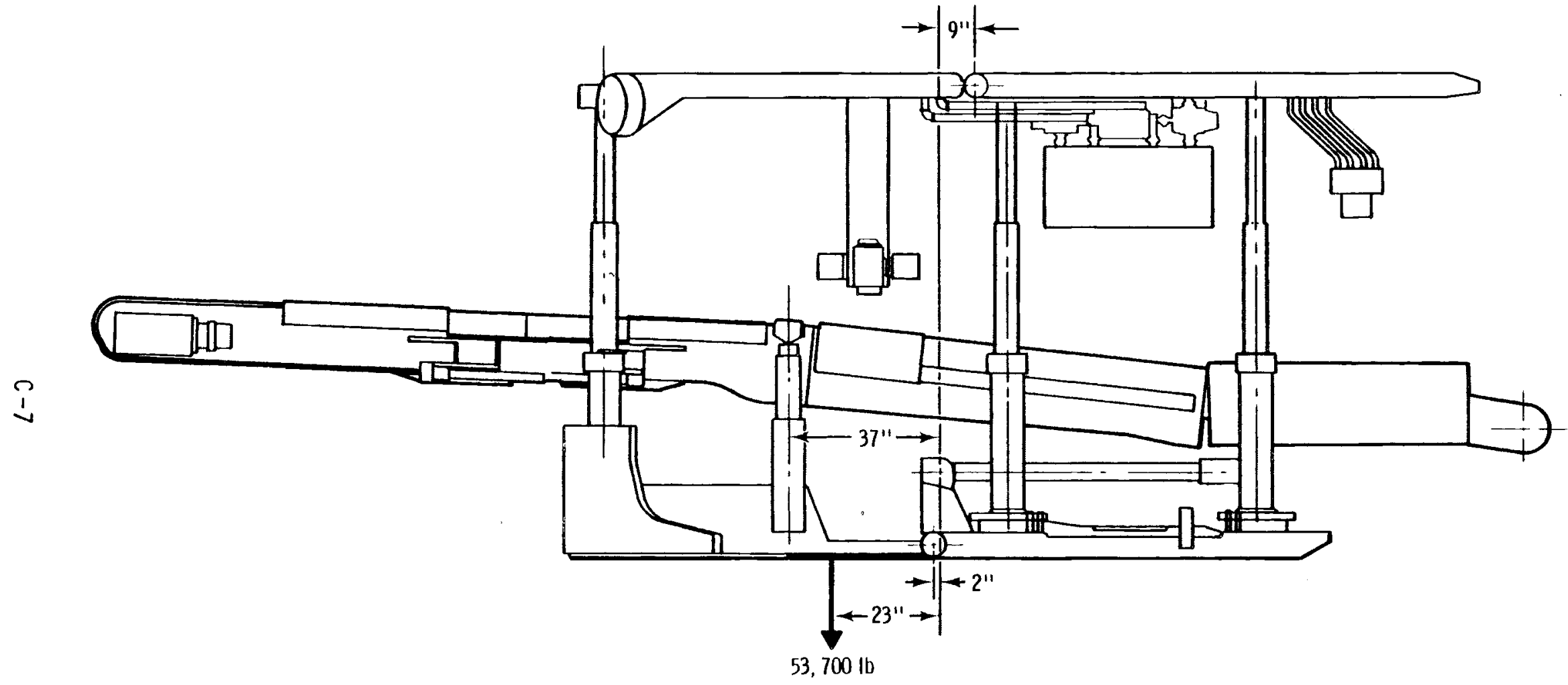

FIGURE C-8. Stationary Rear Portion of AES (Operator's Platform), While Sumping Takes Place, Center of Gravity 


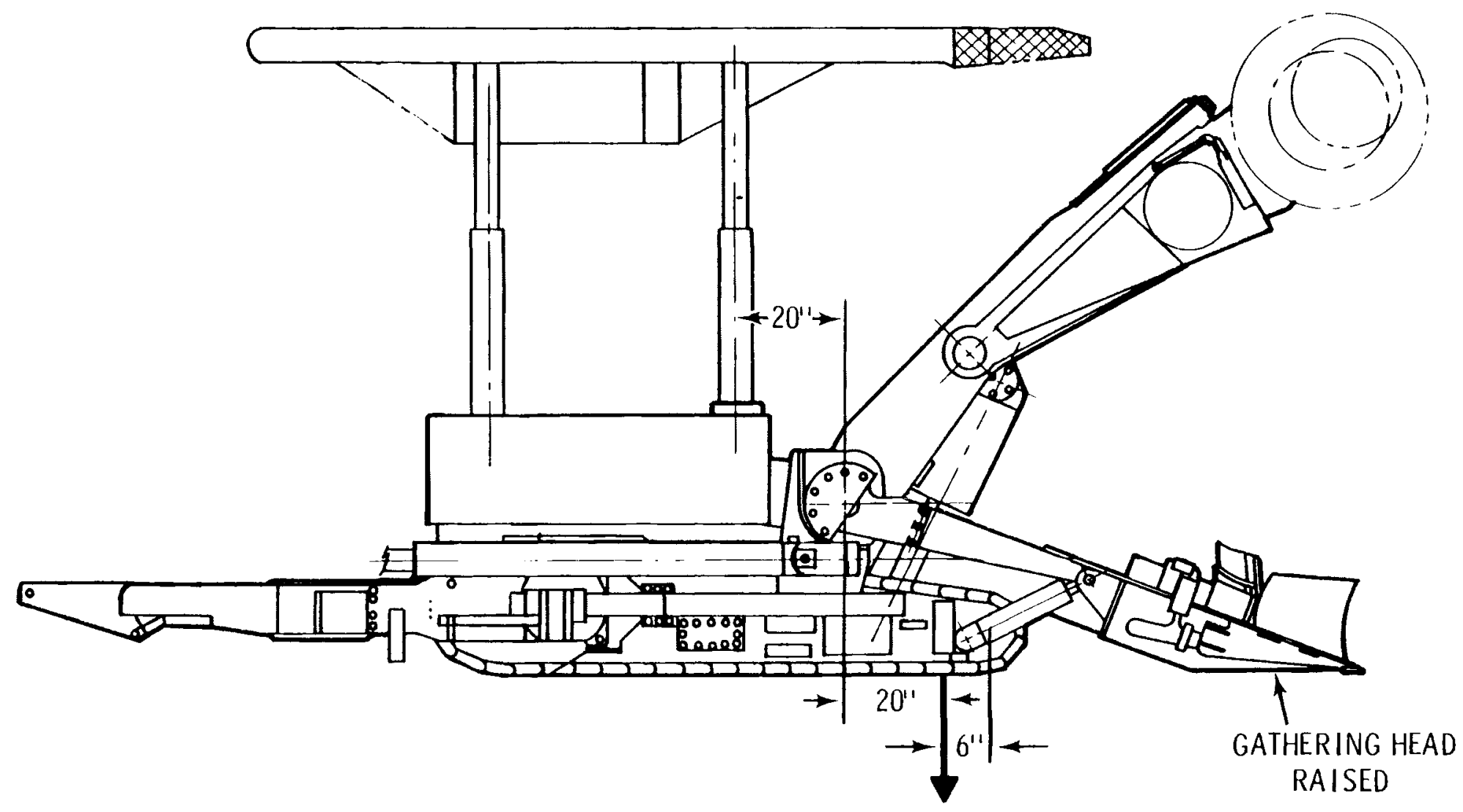

$101,300 \mathrm{lb}$

FIGURE C-9. Sumping Portion of AES Center of Gravity (Excluding the Effect Due to the Stinger Modifications) 


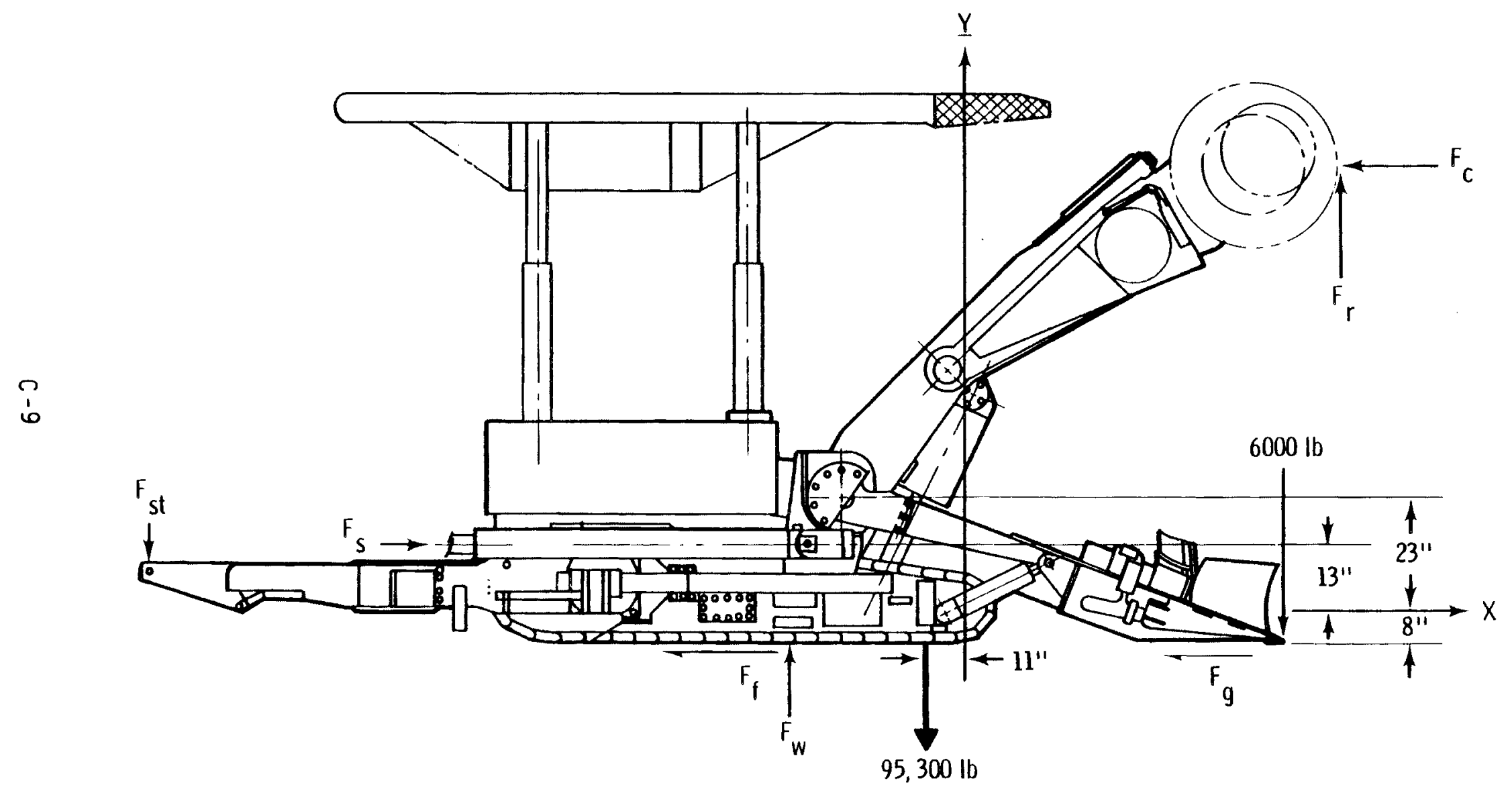

FIGURE C-10. Sumping Portion of AES, With Gathering Head Lowered, Illustrating Acting Forces 
TABLE C-2. Center of Gravity Determination

Center of Gravity Calculations

Stationary rear portion of AES (Figure $\mathrm{C}-8$ )

Distance to

\begin{tabular}{|c|c|c|}
\hline Force & Pivot Point & Force Description \\
\hline$+110001 \mathrm{~b}$ & $\times 27$ in. & rear roof support \\
\hline+13700 & $\times 64$ & operator platform \\
\hline+18000 & $\times 37$ & conveyor \\
\hline-6000 & $\times 63$ & outer roof beams \\
\hline-5000 & $\times 45$ & floor beams \\
\hline
\end{tabular}

$537001 \mathrm{~b} \longrightarrow 23.03$ in. ( - of rear sump cylinder attachment)

Sumping portion of AES (Figure C-9) (gathering head raised)

-37000 1b $\times 93$ in. cutter and boom

$-10000 \times 60 \quad$ gathering head

$+11100 \times 20 \quad$ roof support and misc.

$+43200 \times 41 \quad$ tractor frame

$101300 \mathrm{1b} \longrightarrow 20.22 \mathrm{in.}$ ( $\rightarrow$ of boom pivot)

Sumping portion of AES (Figure C-10) (gathering head lowered)

$-370001 \mathrm{~b} \times 93$ in. cutter and boom

$+4000 \times 0$ gathering head (1owered)

$+11100 \times 20 \quad$ roof support and misc.

$+43200 \times 41$ tractor frame

$95300 \mathrm{lb} \longrightarrow-15.19$ in. ( $\rightarrow$ of boom pivot)

Traming configuration (Figure $\mathrm{C}-11$ )

+53700 1b. $\times 107$ in. rear of AES

$-101300 \times 20$ front

$155000 \mathrm{lb} \longrightarrow 50$ in. ( + of boom pivot) 
to rock forward, which could cause bending or breaking of components and high ground pressures because of the smal1 portion of track area touching the ground.

In the tramming configuration the AES center of gravity is desirably located between the two track axles as shown in Figure $\mathrm{C}-11$. The weight is evenly distributed to the ground at $43.5 \mathrm{psi}$. 


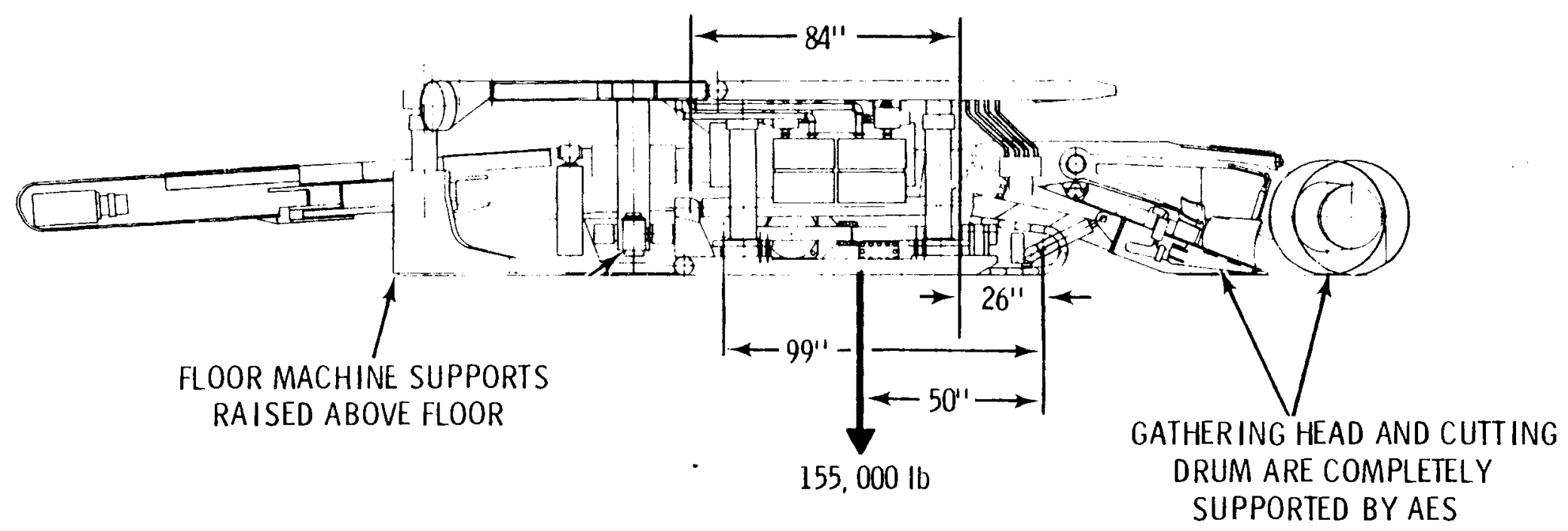

FIGURE C-11. Center of Gravity While AES is Tramming 


\section{FORCE ANALYSIS OF SUMPING SYSTEM}

Many of the problems encountered with the AES occurred during sumping operations. A force analysis was conducted to determine if the cause of the problems could be spotted.

The component force locations are shown in Figure $\mathrm{C}-10$. Their description follows:

$F_{C}$ - force available to sump into coal

$F_{r}$ - vertical coal cutting reaction force $(25,000$ ib maximum)

$F_{s}$ - force applied by hydraulic sumping cylinders

$F_{S}=39.3 \times$ hydraulic pressure in psi

$F_{\text {st }}$ - force applied by hydraulic cylinders as a result of the stinger modification. $F_{s t}=13.1 \times$ hydraulic pressure in psi (see Figure $\mathrm{C}-12$ ). The maximum load which can be applied by the stinger is 39,400 1b occurring at 3000 psi hydraulic pressure.

$F_{f}$ - friction forces caused by a combination of

- track on frame friction

- force to back drive the drive gear train

- sliding friction between the operator platform and the sumping portion of the AES

$F_{g}$ - friction force caused by weight of gathering head on ground when sumping forward. (Gathering head weight on ground is $6000 \mathrm{lb}$. Assuming the coefficient of friction $=0.33$ and $F=\mu \mathrm{N}$, the friction force is equal to 2000 lb.)

$F_{W}$ - effective weight of sumping portion of the AES. The floor loading is increased above the weight of the AES due to the addition of stinger force and decreased due to the vertical coal cutting reaction force.

During sumping operations with the AES, it was found that approximately 1500 psi had to be applied to the sump cylinders before the sumping portion of the AES would move forward to the face of the coal. Additional pressure, higher than $1500 \mathrm{psi}$, was required to force the drum into the coal. The 


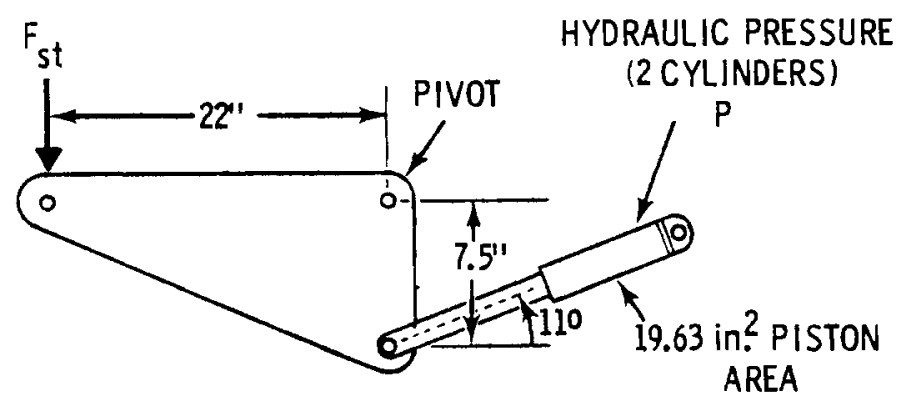

$$
\begin{aligned}
& F_{\text {st }}=\frac{7.5 \text { in. }}{22 \text { in. }} \cdot \cos 11^{\circ} \cdot 19.63 \text { in }^{2} \cdot 2 \text { CYLINDERS } \cdot P(p s i) \\
& F_{s t}=13.1 \text { in? } 2 \cdot P(p s i) \\
& \text { FIGURE C-12. Stinger Lift Capacity }
\end{aligned}
$$

1500-psi cylinder pressure, which represents 59,000 lb of force, is needed primarily to overcome the friction caused by steel-on-steel contact between the cat track shoes and the track frame. The coefficient of friction, $\mu$, for steel-on-steel contact is listed to be $0.8 .{ }^{(1)}$ If this were true, the force required to overcome friction would be approximately $80,000 \mathrm{lb}$ for the 100,000lb sumping portion of the AES. However, because on ly about $60,000 \mathrm{lb}$ are required, $\mu$ is probably in the range of 0.4 to 0.6 . (a)

Equations describing the force balance on the sumping portion of the AES with the gathering head lowered are as follows:

(a) The coefficient of friction is possibly less than 0.8 because spilled hydraulic oil and coal dust are providing some lubrication between the tractor cat track shoes and the track frame. 


$$
\begin{aligned}
\Sigma F_{x}=0= & F_{s}-F_{g}-F_{f}-F_{c}(1 b) \\
\Sigma F_{y}=0= & F_{r}-F_{s t}-95,300+F_{w}(1 b) \\
\Sigma M_{0}=0= & F_{s t} 185+F_{g} 23+95,30011-F_{f} \cdot 8 \\
& -F_{s} \cdot 13+F_{c} \cdot 23^{(a)}-\left(F_{w}\right) \cdot x_{c}(\text { in. }-1 b)
\end{aligned}
$$

Rearranging, the force available for cutting coal is

$$
F_{c}=F_{s}-F_{g}-F_{f},
$$

the force on the Caterpillar tracks is

$$
F_{W}=95,000+F_{\text {st }}-F_{r} \text {, }
$$

and the effective center of gravity for the sumping portion of the AES is

$$
\begin{aligned}
X_{c}= & {\left[F_{s t} \cdot 185+F_{g} \cdot 23+95,300 \cdot 11+F_{c} \cdot 23\right.} \\
& \left.+F_{r} \cdot 132-F_{f} \cdot 8-F_{s} \cdot 13\right] / F_{w}
\end{aligned}
$$

(a) when the center of the cutting drum is near its sumping minimum height of 31 inches above the floor 
Several different forces were applied to the model of the AES sumping portion to determine the changes that occur in the center of gravity and floor loading. Assumptions were made for three types of track floor loading. Their code and description follows:

A - The loading is eventy distributed over the whole Caterpillar type track. The ground contact area is $3564 \mathrm{in.}^{2}$.

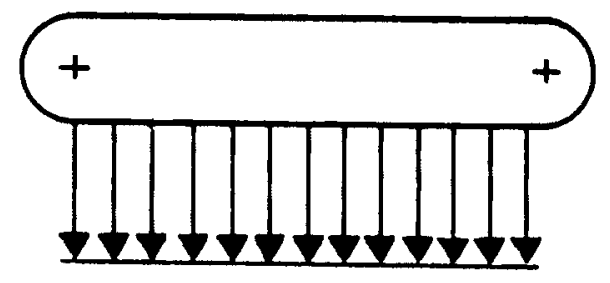

B - The loading is distributed over the whole track but in a triangular distribution centered at the effective center of gravity. The maximum load is listed in Tables $\mathrm{C}-3$ and $\mathrm{C}-4$.

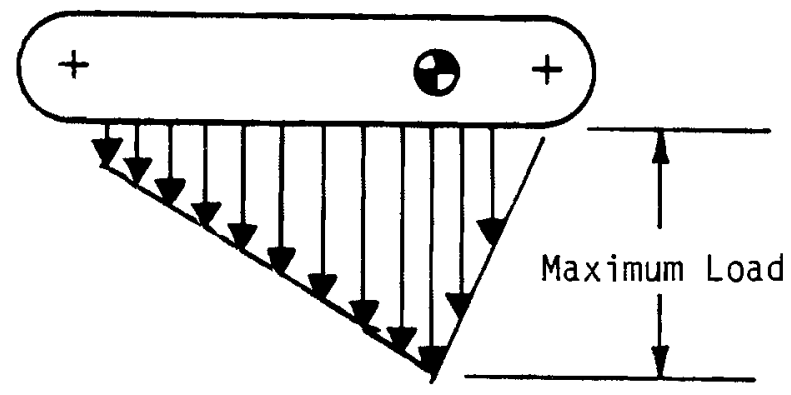


C - The loading is distributed over 2 feet of track length (864 in. ${ }^{2}$ ) centered about the center of gravity.

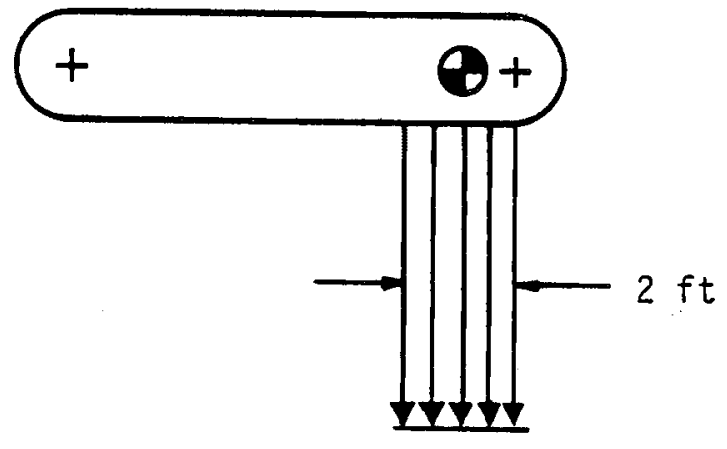

Table C-3 contains the changes in center of gravity that resulted from various loading configurations.

The stinger modification was effective in shifting the center of gravity toward the middle of the tracks. However, additional loading was placed on the tracks, causing the floor loading to increase. As can be seen from Table C-3, without the stinger modification the center of gravity is in front of or near the forward track axle. This causes the sumping portion of the AES to rock about the front axle, potentially bending components and causing very high floor loadings, resulting in the tracks digging into the floor as it moves toward the coal face. When the drum is mining coal, the reaction forces caused by the cutting teeth removing coal provide an upward force that will move the effective center of gravity toward the rear of the tracks and reduce the overall track load. The magnitude of this vertical force under actual operation is unkown but it would be limited to approximately 25,000 lb which is the force available from a 36-in. diameter cutting drum at $57 \mathrm{rpm}$ and powered by two 200 -hp motors. 
TABLE C-3. Center of Gravity and Track Loading for Various Mining Conditions

\begin{tabular}{|c|c|c|c|c|c|c|c|c|c|c|}
\hline & & & & $\mathrm{F}_{\mathrm{r}}$ & & $x^{(a)}$ & & Track Loadi & & \\
\hline No. & $\begin{array}{l}\text { Stst } \\
\text { Stinger } \\
\text { Force } \\
\text { lb (psi) } \\
\end{array}$ & $\begin{array}{c}\text { Sumping } \\
\text { Force } \\
\text { ID (psi) } \\
\end{array}$ & $\begin{array}{l}\text { Friction } \\
\text { Force } \\
\text { Ib } \\
\end{array}$ & $\begin{array}{l}\text { Reaction } \\
\text { Force } \\
\text { Ib }\end{array}$ & $\begin{array}{c}\text { Cutt ing } \\
\text { Force } \\
\text { lb }\end{array}$ & $\begin{array}{l}\text { Center of } \\
\text { Gravity } \\
-+ \text { (in.) }-+\end{array}$ & $\underset{\mathrm{Ib}_{\mathrm{b}}}{\mathrm{F}_{\mathrm{W}}}$ & $\begin{array}{c}A \\
p s i \\
\left(3564 \quad i^{2}\right) \\
\end{array}$ & $\begin{array}{r}B(\max ) \\
\mathrm{psi} \\
\left(3564 \mathrm{in}^{2}\right) \\
\end{array}$ & $\begin{array}{c}c \\
\text { psi } \\
\left(864 \text { in }^{2}\right) \\
\end{array}$ \\
\hline 1 & 0 & $\begin{array}{l}59,000 \\
(1500)\end{array}$ & 57,000 & 0 & 0 & +1.4 & 95,300 & 26.7 & 53.5 & 110.3 \\
\hline 2 & $\begin{array}{l}6,550 \\
(500)\end{array}$ & $\begin{array}{l}59,000 \\
(1500)\end{array}$ & 57,000 & 0 & 0 & -10.6 & 101,850 & 28.6 & 57.2 & 117.9 \\
\hline 3 & $\begin{array}{l}13,140 \\
(1000)\end{array}$ & $\begin{array}{l}59,000 \\
(1500)\end{array}$ & 57,000 & 0 & 0 & -21.2 & 108,440 & 30.4 & 60.9 & 125.5 \\
\hline 4 & $\begin{array}{l}19,710 \\
(1500)\end{array}$ & $\begin{array}{l}59,000 \\
(1500)\end{array}$ & 57,000 & 0 & 0 & -30.6 & 115,010 & 32.3 & 64.5 & 133.1 \\
\hline 5 & $\begin{array}{l}26,280 \\
(2000)\end{array}$ & $\begin{array}{l}59,000 \\
(1500)\end{array}$ & 57,000 & 0 & 0 & -38.9 & 121,580 & 34.1 & 68.2 & 140.7 \\
\hline 6 & 0 & $\begin{array}{l}78,500 \\
(2000)\end{array}$ & 57,000 & 25,000 & 19,500 & -35.3 & 70,300 & 19.7 & 39.5 & 81.4 \\
\hline 7 & $\begin{array}{l}6,550 \\
(500)\end{array}$ & $\begin{array}{l}78,500 \\
(2000)\end{array}$ & 57,000 & 25,000 & 19,500 & -44.9 & 76,850 & 21.6 & 43.1 & 88.9 \\
\hline 8 & $\begin{array}{l}13,140 \\
(1000)\end{array}$ & $\begin{array}{l}78,500 \\
(2000)\end{array}$ & 57,000 & 25,000 & 19,500 & -53.5 & 83,400 & 23.4 & 46.8 & 96.5 \\
\hline 9 & $\begin{array}{l}19,710 \\
(1500)\end{array}$ & $\begin{array}{l}78,500 \\
(2000)\end{array}$ & 57,000 & 25,000 & 19,500 & -61.0 & 90,000 & 25.3 & 50.5 & 104.2 \\
\hline 10 & $\begin{array}{l}26,280 \\
(2000)\end{array}$ & $\begin{array}{l}78,500 \\
(2000)\end{array}$ & 57,000 & 25,000 & 19,500 & -67.7 & 96,600 & 27.1 & 54.2 & 111.8 \\
\hline 11 & 0 & $\begin{array}{l}98,250 \\
(2500)\end{array}$ & 57,000 & 25,000 & 39,250 & -37.4 & 70,300 & 19.7 & 39.5 & 81.4 \\
\hline 12 & $\begin{array}{l}6,550 \\
(500)\end{array}$ & $\begin{array}{l}98,250 \\
(2500)\end{array}$ & 57,000 & 25,000 & 39,250 & $\begin{array}{l}-46.9 \\
-\end{array}$ & 76,850 & 21.6 & 43.1 & 88.9 \\
\hline 13 & $\begin{array}{l}13,140 \\
(1000)\end{array}$ & $\begin{array}{l}98,250 \\
(2500)\end{array}$ & 57,000 & 25,000 & 39,250 & -55.3 & 83,400 & 23.4 & 46.8 & 96.5 \\
\hline 14 & $\begin{array}{l}19,710 \\
(1500)\end{array}$ & $\begin{array}{l}98,250 \\
(2500)\end{array}$ & 57,000 & 25,000 & 39,250 & -62.7 & 90,000 & 25.3 & 50.5 & 104.2 \\
\hline 15 & $\begin{array}{l}26,280 \\
(2000)\end{array}$ & $\begin{array}{l}98,250 \\
(2500)\end{array}$ & 57,000 & 25,000 & 39,250 & -69.3 & 96,600 & 27.1 & 54.2 & 111.8 \\
\hline
\end{tabular}


ROOF AND FLOOR LOADING

An analysis of the roof and floor support system was conducted to determine the magnitude of the average loading and the thrust that can be applied by the AES.

The inner roof support is actuated by four hydraulic cylinders. The loads applied to the roof and the reaction force applied to the tracks for various hydraulic pressures are shown in Table $\mathrm{C}-4$. As can be seen, the reaction to the roof loads causes large ground pressure to be exerted by the tracks.

The roof supports and floor machine supports (excluding the inner roof support) are actuated by six hydraulic cylinders; their force is assumed to be distributed evenly over the support surfaces. The loads that can be applied to the roof and floor at various hydraulic pressures are contained in Table C-5.

The thrust that can be applied to the AES sumping portion is dependent upon the reaction force that the rear portion can withstand wedged between the roof and the floor with the roof support system. The reaction force is dependent upon the force applied to the floor and the coefficient of fraction between the floor machine supports and the floor.

Due to the stinger modification, in which force is applied to the rear of the tracked frame forcing the acting center of gravity rearward, the force loading on the roof and floor machine supports is altered. The stinger moves in a track contained in the operators platform, which is part of the floor machine supports. The roof support cylinders are attached to the floor machine supports. Therefore, when force is applied by the stinger to push down on the rear of the tractor frame, the reaction force reduces the loading on the floor machine supports. Because sumping forces are transmitted to the floor by friction between the floor supports and the floor, this reduced loading reduces the available sumping force. 
TABLE C-4. Inner Roof Support Loading

\begin{tabular}{|c|c|c|c|c|c|c|}
\hline \multirow{2}{*}{$\begin{array}{l}\text { Cylinder } \\
\text { Pressure } \\
\text { (psi) }\end{array}$} & \multirow{2}{*}{$\begin{array}{l}\text { Lopding on Roof Due } \\
\text { To Cylinder Pressure } \\
\text { Minus } 11,100 \text { ib Support Wt } \\
\text { (1b) }\end{array}$} & \multirow{2}{*}{$\begin{array}{l}\text { Average Roof }(b) \\
\text { Loading } \\
\text { (psi) }\end{array}$} & \multirow{2}{*}{$\begin{array}{l}\text { Total Force } \\
\text { On Tracks } \\
\text { (1b) }\end{array}$} & \multicolumn{3}{|c|}{$\begin{array}{l}\text { Track Loading Assum- } \\
\text { ing Three Distribu- } \\
\text { tions (psi) }\end{array}$} \\
\hline & & & & $A$ & $B$ & $C$ \\
\hline 500 & 36,370 & 4.30 & 131,600 & 36.9 & 73.8 & 152.3 \\
\hline 1000 & 83,830 & 9.92 & 179,130 & 50.3 & 100.5 & 207.3 \\
\hline 2000 & 178,770 & 21.16 & 274,070 & 76.9 & 153.8 & 317.2 \\
\hline 3000 & 273,700 & 32.39 & 369,000 & 103.5 & 207.1 & 427.1 \\
\hline
\end{tabular}

(a) Effective cylinder bore area is $23.7 \mathrm{in}^{2}$ for each of the four cylinders.

(b) Inner roof support area is $8450 \mathrm{in}^{2}$.

(c) Track frame weight of $84,200 \mathrm{lb}$ is added to the reaction of the force which is applied to the roof. 
TABLE C-5. Roof and Floor Loading From Outer and Rear Supports

Roof Loading (average loading over rear and outer roof supports)

\begin{tabular}{|c|c|c|c|}
\hline $\begin{array}{l}\begin{array}{c}\text { Cylinder Pressure } \\
\text { (psi) }\end{array} \\
500\end{array}$ & $\begin{array}{l}\text { Loading Due to } \\
\text { Cylinder Pressure } \\
\text { Minus } 17,000 \text { 1b Support wt. (a) } \\
\frac{(1 \mathrm{~b})}{54,200}\end{array}$ & $\begin{array}{l}\text { Loading } \\
\frac{\text { (psi) }^{(b)}}{6.37}\end{array}$ & $\begin{array}{l}\text { With Max. Stinger }(c \\
\text { Force of } 39,4001 b \\
\frac{(p s i)}{10.99}\end{array}$ \\
\hline 1000 & 125,400 & 14.74 & 19.36 \\
\hline 2000 & 267,800 & 31.47 & 36.09 \\
\hline 3000 & 410,200 & 48.20 & 52.82 \\
\hline
\end{tabular}

Floor Loading (average loading over floor machine supports)

\begin{tabular}{ccccc}
$\begin{array}{c}\text { Cylinder Pressure } \\
\text { (psi) }\end{array}$ & $\begin{array}{c}\text { Weight of Supports Plus } \\
\text { Loading Due to Six Cylinders }\end{array}$ (d) & $\begin{array}{c}\text { Loading }(e) \\
\text { (psi) }\end{array}$ & $\begin{array}{c}\text { Loading Minus Max. Stinger } \\
\text { Force of } 39,400 \text { 1b } \\
\text { (psi) }\end{array}$ \\
\cline { 2 - 3 } 500 & 107,900 & 14.23 & 9.03 & 18.43 \\
1000 & 179,100 & 23.63 & 37.21 \\
2000 & 321,500 & 42.41 & 56.00
\end{tabular}

(a) Effective cylinder bore area is $23.7 \mathrm{in}^{2}$ for each of the six cylinders.

(b) The rear and outer roof supports area is $8510 \mathrm{in}^{2}$.

(c) This loading is possible only if the stinger load is applied after the roof and floor machine supports have been loaded.

(d) The floor machine supports weigh $36,7001 \mathrm{~b}$.

(e) The floor machine support area is $7580 \mathrm{in}^{2}$. 
Table C-6 shows the thrust available for various hydraulic support cylinder pressures and coefficients of friction. A coefficient of friction equal to 0.6 is felt to be the maximum obtainable between the floor supports and the floor.

Table $C-7$ shows the decrease in thrust that results when force is removed from the rear floor support due to the stinger modification for various coefficients of friction. As an example, at a floor loading cylinder hydraulic pressure of $1000 \mathrm{psi}$ and a floor coefficient of friction of 0.6 , the maximum sumping force without stinger pressure is 107,460 lb. If the stinger cylinder is activated to prevent digging-in of the sumping assembly, the maximum sumping force is reduced over 23,000 lb to $83,800 \mathrm{lb}$. Thus, although the stinger modification has eliminated the problem of excessive floor loading at the front of the tracks, it has created a potential new problem by limiting sumping force.

TABLE C-6. Available Sumping Thrust for Various Friction Coefficients Between the Ground and the Floor Machine Supports (Without Stinger Force)

Floor Loading Cylinder Hydraulic Pressure (psi)

Floor Loading (a) Maximum Thrust (1b) for Friction Coefficients of $\mu=$

$\begin{array}{rrrrrrrrr}500 & 107,900 & 10,790 & 21,580 & 32,370 & 43,160 & 53,950 & 64,740 \\ 750 & & 143,400 & 14,340 & 28,680 & 43,020 & 57,360 & 71,700 & 86,040 \\ 1000 & 179,100 & 17,910 & 35,820 & 53,730 & 71,640 & 89,550 & 107,460 \\ 2000 & 321,500 & 32,150 & 64,300 & 96,450 & 128,600 & 160,750 & 192,900 \\ 3000 & 463,900 & 46,390 & 92,780 & 139,170 & 185,560 & 231,950 & 278,340\end{array}$

(a) Data taken from Table $\mathrm{C}-5$. 
TABLE C-7. Available Sumping Thrust for Various Friction Coefficients Between the Ground and the Floor Machine Supports (With

Maximum Stinger Force of 39,400 lb)

\begin{tabular}{|c|c|c|c|c|c|c|c|}
\hline $\begin{array}{l}\quad \text { Floor } \\
\text { Loading } \\
\text { Cylinder } \\
\text { Hydraulic } \\
\text { Pressure } \\
\text { (psi) } \\
\end{array}$ & $\begin{array}{l}\text { Floor } \\
\text { Loading } \\
\text { (1b) }\end{array}$ & $\frac{\text { Maximum }}{0.10}$ & $\begin{array}{c}\text { Thrust } \\
\underline{0.20}\end{array}$ & (b) for $F$ & $\frac{\text { riction } \mathrm{Co}}{0.40}$ & $\frac{\text { efficient }}{\underline{0.50}}$ & $\frac{s \text { of } \mu}{\underline{0.60}}$ \\
\hline 500 & 68,500 & 6,850 & 13,700 & 20,550 & 27,400 & 34,250 & 41,100 \\
\hline 750 & 104,000 & 10,400 & 20,800 & 31,200 & 41,600 & 52,000 & 62,400 \\
\hline 1000 & 139,700 & 13,970 & 27,940 & 41,910 & 55,880 & 9,850 & 83,820 \\
\hline 2000 & 282,100 & 28,210 & 56,420 & 84,630 & 112,840 & 141,050 & 169,260 \\
\hline 3000 & 424,500 & 42,450 & 84,900 & 127,350 & 169,800 & 212,250 & 254,700 \\
\hline
\end{tabular}




\section{CONCLUSIONS}

The foregoing analysis is of value because it helps identify specific causes of the following problems observed during testing:

1. degradation of the floor after repeated tramming of the AES over an area - This is caused by the excessive loading (over 43 psi) placed on the floor by the weight of the AES. Recommended maximum floor loading is on the order of 25 psi.

2. failure of the floor at the front of the tracks as the cutting assembly was sumped toward the face - This was caused by the forward location of the center of gravity of the cutting assembly. It was accentuated by the location of the sump cylinder attachment points and high friction forces in the track assembly, which combined to make the tracks rock forward during sumping.

3. improvement of the floor loading problems during sumping after completion of the stinger modification - The stinger modification prevented rocking of the track assembly and helped to more evenly distribute the track forces on the floor.

4. limited sumping force, particularly after the stinger modification This was caused by the large friction resistance in the tracks and accentuated by the stinger modification, which served to reduce the amount of sumping force that could be transmitted to the floor by the floor machine supports.

This analysis has identified problem areas observed during testing and has suggested the causes of these problems. This fact indicates that this type of analysis should be carried out for any future AES design.

\section{REFERENCE}

1. Handbook of Tables for Applied Engineering Science. The Chemical Rubber Co., Cleveland, OH, p. 507, 1970. 


\section{DISTR IBUTION LIST}

No. of

Copies

OFFSITE

U.S. Department of Energy

A. A. Churm

Chicago Patent Group

9800 South Cass Avenue

Argonne, IL 60439

27 DOE Technical Information Center

10 John Karhnak

Division of Fossil Fuel Extraction

U.S. Department of Energy

Mai] Drop D-107

Washington, DC 20545

6 Mike Mahaffey

Pittsburgh Mining Operation

4800 Forbes Ave.

Pittsburgh, PA 15213

2 Dick Farrar

U.S. Department of Energy

Carbondale Mining Technology Center

Carbondale, IL 62901
No. of

Copies

ONSITE

DOE Richland Operations Office Energy Programs Division

H. E. Ransom

20

Pacific Northwest Laboratory

J. D. Eklund

J. M. Halter

W. S. Kelly

H. L. Parry (5)

L. T. Pedersen (2)

P. L. Peterson (2)

R. G. Sullivan

Technical Information (5)

Publishing Coordination (2) 
. 